



\section{About the Cover}

Technologies developed at Lawrence Livermore are successfully cleaning up the groundwater beneath a utility pole yard in Visalia, California. Helped by Livermore researchers as operational consultants, Southern California Edison and SteamTech Environmental Services are using the dynamic underground stripping and hydrous pyrolysis/oxidation techniques to remove contaminants at an astounding rate $-5,000$ times that of conventional treatment.

\section{What Do You Think?}

We want to know what you think of our publication. Please use the enclosed survey form to give us your feedback.

\section{Electronic Access}

$S \& T R$ is available on the Internet at http://www.llnl.gov/str. As references become available on the Internet, they will be interactively linked to the footnote references at the end of each article. If you desire more detailed information about an article, click on any reference that is in color at the end of the article, and you will connect automatically with the reference.

\section{About the Review}

Lawrence Livermore National Laboratory is operated by the University of California for the Department of Energy. At Livermore, we focus science and technology on assuring our nation's security. We also apply that expertise to solve other important national problems in energy, bioscience, and the environment. Science \& Technology Review is published ten times a year to communicate, to a broad audience, the Laboratory's scientific and technological accomplishments in fulfilling its primary missions. The publication's goal is to help readers understand these accomplishments and appreciate their value to the individual citizen, the nation, and the world.

Please address any correspondence (including name and address changes) to $S \& T R$, Mail Stop L-664, Lawrence Livermore National Laboratory, P.O. Box 808, Livermore, California 94551, or telephone (925) 422-8961. Our electronic mail address is hunter6@llnl.gov. 


\section{S\&TR Staff}

\section{SCIENTIFIC EdITOR \\ J. Smart}

MANAGing Editor

Sam Hunter

Publication Editor

Sue Stull

\section{WrITERS}

Arnie Heller, Lori McElroy, Katie Walter, and Gloria Wilt

\section{Art Director AND Designer \\ Ray Marazzi}

INTERNET DESIGNER

Kitty Tinsley

\section{CoMPOSITOR}

Louisa Cardoza

\section{Proofreader}

Al Miguel

$S \& T R$ is a Director's Office publication, produced by the Technical Information Department, under the direction of the Office of Policy, Planning, and Special Studies.

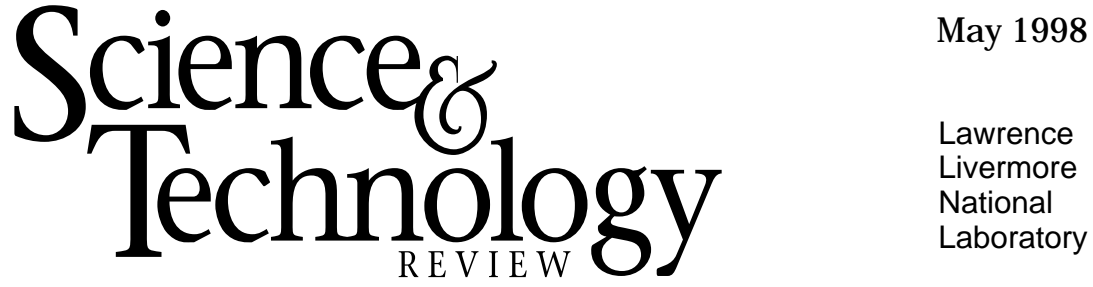

2 The Laboratory in the News

3 Commentary by J ay Davis Changing the Game

\section{Features}

4 They All Like It Hot: Faster Cleanup of Contaminated Soil and Groundwater

In a hundredth the time of the original estimate, cleanup of a heavily contaminated Superfund site in California's Central Valley progresses, using methods developed at Lawrence Livermore.

\section{Computational Mechanics Moves Ahead}

The Engineering Directorate's Methods Development Group has produced advanced modeling and simulation tools that solve an ever-widening range of engineering problems.

\section{Research Highlights}

20 Corsica: Integrated Simulations for Magnetic Fusion Energy

23 Device Assembly Facility: New Facilities for Handling Nuclear Explosives

\section{Patents and Awards}

\section{Abstracts}

Printed in the United States of America

\section{Available from}

National Technical Information Service U.S. Department of Commerce

5285 Port Royal Road

Springfield, Virginia 22161

\section{UCRL-52000-98-5}

Distribution Category UC-700

May 1998

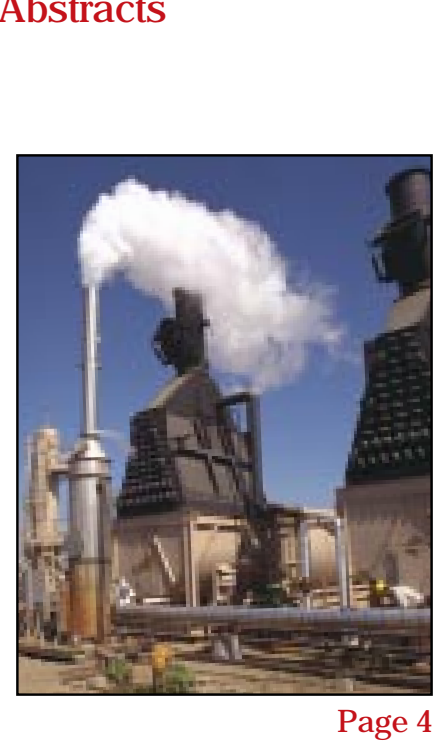

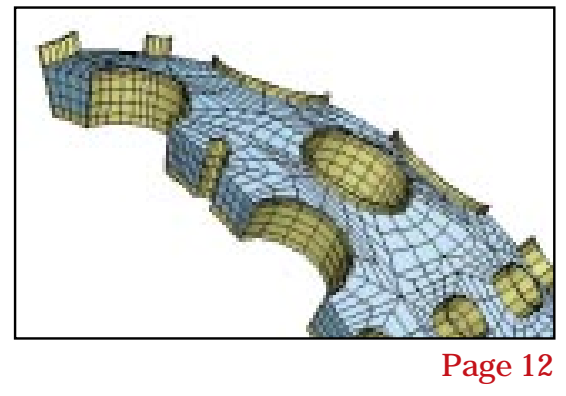



Page 23 


\section{Lab help for BART high-tech training}

Representatives from BART (Bay Area Rapid Transit), Lawrence Livermore National Laboratory, and Chabot-Las Positas Community College District met with U.S. Congresswoman Ellen Tauscher to sign a Memorandum of Agreement to develop high-tech training tools for rapid-transit train operators. The result will be performance-based training that includes enhanced curricula, updated methodology, and high-tech simulations. The curricula will help focus training on the areas of highest need in the shortest possible time.

Lawrence Livermore will provide scientific and technical expertise for identifying and recommending training delivery methodology and equipment: computer simulation of complex systems, advanced sensors and instrumentation, transportation studies, and diverse engineering capabilities. The Chabot-Las Positas Community College District will design performanceoutcome, competency-based curricula. BART brings extensive experience and expertise in all areas of public rapid transit operations, workforce development, safety, and customer service.

Livermore Deputy Director for Science and Technology Jeff Wadsworth said, "This partnership represents a welcome opportunity to apply the Laboratory's state-of-the-art capabilities and scientific expertise to a real problem in the Bay Area. Improved training programs and facilities for rapid transit operators benefit our community."

Contact: Elizabeth Rajs (925) 424-5806 (rajs1@IInl.gov).

\section{Kidney disease gene found}

Years invested in building a human genetic roadmap are yielding big-time benefits. Lawrence Livermore National Laboratory scientists have teamed with international collaborators to pinpoint the location of a gene responsible for causing a kidney disease. This effort is described in a research paper in the March 1998 issue of Molecular Cell.

Scientists at Livermore's Human Genome Center collaborated with researchers from the Karolinska Institute in Stockholm, Sweden, and the University of Oulu in Oulu, Finland. Together, the three institutions discovered the gene for congenital nephrotic syndrome, a deadly disease that causes massive amounts of proteins to be excreted from the body. The gene is located on chromosome 19.
A progressive disease, congenital nephrotic syndrome usually leads to death by age 2 . The only life-saving alternative is a kidney transplant. The disease is most prevalent in Finland, striking about one in 10,000 Finnish children, but occurring with a significantly lower frequency in other nations. The discovery has already yielded immediate clinical assistance, enabling development of a diagnostic tool to identify carriers of the gene.

To date, Livermore's Human Genome Center has mapped most of chromosome 19. It has also sequenced, or ordered, the base pairs for about 3.5 million of the chromosome's 65 million bases, in a process that is accelerating with the development of new technologies. The Center has assisted collaborators in discovering the genes for a variety of diseases, including myotonic dystrophy, a disease that affects about one in 8,000 adults worldwide; the genetic cause of two forms of dwarfism; a gene for migraine headaches; and the PeutzJeghers syndrome gene. Additionally, Lab researchers also joined in the effort to find a gene for cadasil, a type of stroke. Contact: Public Affairs Office (925) 423-3107 (wampler1@IInl.gov).

\section{New associate director for Energy}

Director Bruce Tarter named Terry Surles the new Energy Associate Director, commenting that Surles "brings to this position proven leadership in building large programs and currency with the issues and players in the broad energy and environmental arena. It is becoming increasingly clear to me that the development, assessment, and application of energy technologies will play a stronger role in national policy and practice. I look forward to working with Dr. Surles and the Energy Directorate to make substantial contributions to such a crucial national issue."

Surles most recently was the deputy secretary for science and technology for the California Environmental Protection Agency. Prior to that he served at Argonne National Laboratory in the environmental and energy areas and was the general manager of Environmental Programs from 1993 to 1997. He received his bachelor's degree in chemistry from St. Lawrence University in 1966 and his doctorate in analytical chemistry from Michigan State University in 1970. He joined Argonne in 1978 after serving posts in academia and private industry. A member of the American Association for the Advancement of Science and the American Chemical Society, he has published more than 30 peer-reviewed journal articles and 70 technical reports. 




\section{Changing the Game}

$T_{\mathrm{re}}^{\mathrm{H}}$ HE Department of Energy's cleanup problems are often represented as intractable. The cleanup budget, now the largest single component in DOE's budget, is seen as inadequate, unlikely to decrease, and detrimental to other DOE functions. Although unique problems with poorly contained and characterized radioactive wastes dominate DOE's problems, the issue of spills and plumes of conventional materials such as solvents, fuels, and mixtures of organic materials is significant, too. Estimates have shown that DOE has a \$10-billion legacy of such plumes to clean up. The total cost of cleaning Department of Defense and industrial sites across the country is larger still. When Laboratory Director Bruce Tarter established the Earth and Environmental Sciences Directorate in 1994, he challenged us to change the game in environmental cleanup. The story of the Visalia pole yard in this issue of $S \& T R$ (beginning on p. 4) demonstrates the first success in response to that challenge.

Plumes of contaminants in groundwater pose several problems: hazards to public safety and health when the water is used, cleanup cost burdens to property owners, and, because of the associated liabilities, transfer of property ownership. While transferring property is not a burden to most DOE sites (which are likely to remain in government possession indefinitely), it is an obstacle to DOD site closure and reuse of valuable lands (such as California's Mare Island or Alameda Naval Air Station).

Remediation steps to date commonly rely on pump-and-treat. That method works well for near-term regulatory compliance (the site owner is doing something in good faith) to control the spread of plumes, but it rarely removes all the contaminants. Toxic compounds in spills have had decades to sink and bind to fine silts and clays. They are unlikely to be removed by simply slowly flushing water through them.

Steam applied to the subsurface environment mobilizes difficult materials such as heavy oils, which can be extracted at greatly accelerated rates. The addition of oxygen through air injection further destroys contaminant materials. (Remember the elementary chemistry lesson that water at $100^{\circ} \mathrm{C}$ is a very reactive substance.) As an added benefit, heating the subsurface promotes the growth of thermophylic bacteria that move into a warmed region and actively bioremediate remaining traces of contaminants.
The technical success of Visalia resulted from finding a corporate sponsor, Southern California Edison, that was willing to invest the funds up front for a significant deployment of a new technology at the scale (\$20 million) required for a substantive engineering and economic test. DOE sites tend to be constricted by budgets annually competing for money to complete scheduled tasks, producing a context in which "experiments of scale" are perceived as activities that divert funds from ongoing remediation or delay tasks required under Records of Decision. A corporation understands the value of accelerating cleanup and moving the liability off its books, which DOD now finds attractive as well.

Lawrence Livermore's role in this project was to develop and demonstrate relevant cleanup and diagnostic techniques on its own site and then transfer the technologies to a corporate partner who owns a Superfund site and to a subcontractor with steam-injection experience. We functioned as a supporting science and technology team, bringing our experience in supercomputer modeling of subsurface flow and reactive transport, rare-gas tracers and electrical tomographic diagnostics, and isotopic analyses to validate results. These tools are not available in the commercial sector, and the processes are not readily done by the academic community, proving that there is a role for a national laboratory in solving this problem. Some of these tools, now in the hands of the industrial participants, are available for use at other sites.

We now are exploring with DOE and other agencies the next possible sites for testing these techniques. At each site, we will encounter a new combination of subsurface variables and a new cocktail of contaminants. The remediation process will have to be validated anew on each site-we have no silver bullets for subsurface contamination.

As we work at these sites, more technology, understanding, and tricks of the trade will move into industrial hands. The rewards for us will be in helping to remove pressing health hazards cost effectively throughout the nation and gaining future support to move on to the next set of "intractable" problems.

Jay C. Davis is Associate Director, Earth and Environmental Sciences. 
They All Like It Hot: Faster Cleanup of Contaminated Soil and Gr oundw ater

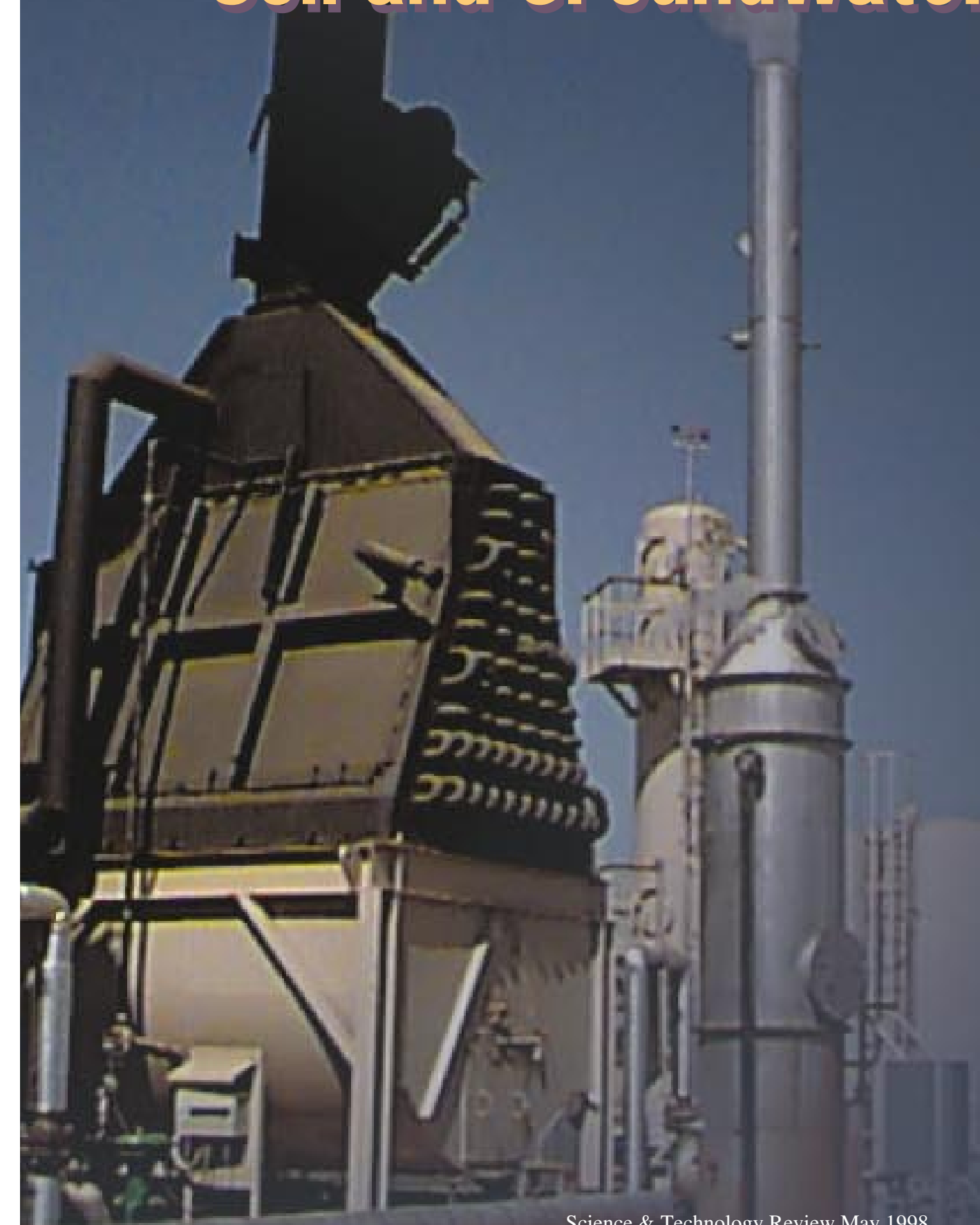

C LEAN up a greasy kitchen spill with Use hot water instead, and progress improves markedly. So it makes sense that cleanup of greasy underground contaminants such as gasoline might go faster if hot water or steam were somehow added to the process.

The Environmental Protection Agency named hundreds of sites to the Superfund list-sites that have been contaminated with petroleum products or petroleum products or solvents. Elsewhere across the country, thousands of properties not identified on federal cleanup lists are contaminated as well. Given that under current regulations, underground accumulations of solvent and hydrocarbon contaminants (the most serious cause of groundwater pollution) must be cleaned up, finding a rapid and effective method of removing them is imperative.

In the early 1990s, in collaboration with the School of Engineering at the University of California at Berkeley, Lawrence Livermore developed dynamic underground stripping. (For an explanation of this method, see Energy \& Technology Review,

pp. 1-7). This method for treating underground contaminants with heat is much faster and more effective than 


\section{The original estimate to clean the Visalia Superfund site was more than 100 years. Using technologies developed at Lawrence Livermore, cleanup is happening in one to two years and at a much lower cost than with pump-and-treat methods.}

traditional treatment methods. More recently, Livermore scientists developed hydrous pyrolysis/oxidation, a process that converts contaminants in the ground to such benign products as carbon dioxide, chloride ions, and water. By introducing both heat and oxygen, this process has effectively destroyed all petroleum and solvent contaminants that have been subjected to laboratory tests.

During the summer of 1997, both processes were used for cleanup of a four-acre site in Visalia, California, owned by Southern California Edison (Figure 1). The utility company had used the site for 80 years to treat utility poles by dipping them into creosote, a pentachlorophenol compound, or both. By the 1970s, these highly toxic substances had seeped into the subsurface to depths of approximately 100 feet (30 meters). The Visalia pole yard bore the distinction of being one of the original Superfund sites.

Southern California Edison and SteamTech Environmental Services of Bakersfield, California (the first commercial site licensee of the dynamic underground stripping technology), are cleaning up the Visalia site, with Livermore staff periodically on hand as operational consultants.
During the first six weeks of operation, between June and August 1997, the team removed or destroyed in place approximately 300,000 pounds (135 metric tons) of contaminants, a rate of about 46,000 pounds (22 metric tons) per week (Figures 2 and 3 ). For nearly 20 years, Southern California Edison had been removing contaminants from the subsurface using the standard cleanup method, known as pump-andtreat, most recently at a rate of just 10 pounds (0.03 metric ton) per week. In contrast, the amount of hydrocarbons removed or destroyed in place in those six weeks was equivalent to 600 years of pump-and-treat, about 5,000 times the previous removal rate. Needless to say, the Visalia cleanup using dynamic underground stripping plus hydrous pyrolysis/oxidation is considered a wild success by everyone involved.

Geophysicist Robin Newmark and geochemist Roger Aines are Lawrence Livermore project leaders for the work at Visalia. Says Aines, "No one really knew what was underground at Visalia. Through the winter of 1998, Southern California Edison and SteamTech have removed over 540,000 pounds (245 metric tons), and the job still isn't finished. However, contaminant concentrations in recovered groundwater continue to drop, so we know the end is in sight."

\section{Finding a Better Way}

For years, scientists in Livermore's Earth and Environmental Sciences Directorate have been researching better methods to clean up soil and groundwater contamination, in part because both the Livermore site and Livermore's Site 300 are also Superfund sites as a result of U.S. Navy, Atomic Energy Commission, and DOE operations. Most contaminants at the Livermore sites are either petroleum distillates (e.g., gasoline, diesel fuel) or chlorinated hydrocarbons used as solvents. Existing methods to remove these compounds from soil and groundwater have halted their migration off the site, but cleanup will still take a decade or more to complete.

For about 20 years, the traditional method of cleaning up contaminated groundwater has been the pump-andtreat method. Water is pumped from the water table to the ground surface, treated to remove or destroy contaminants, and returned underground. Huge amounts of water must be flushed through the contaminated area for years or even decades to clean it, and even then the contamination may not be completely removed. 
Says Newmark, "Some of the solvents and other contaminants have very low solubility. So very small amounts can pollute millions of gallons

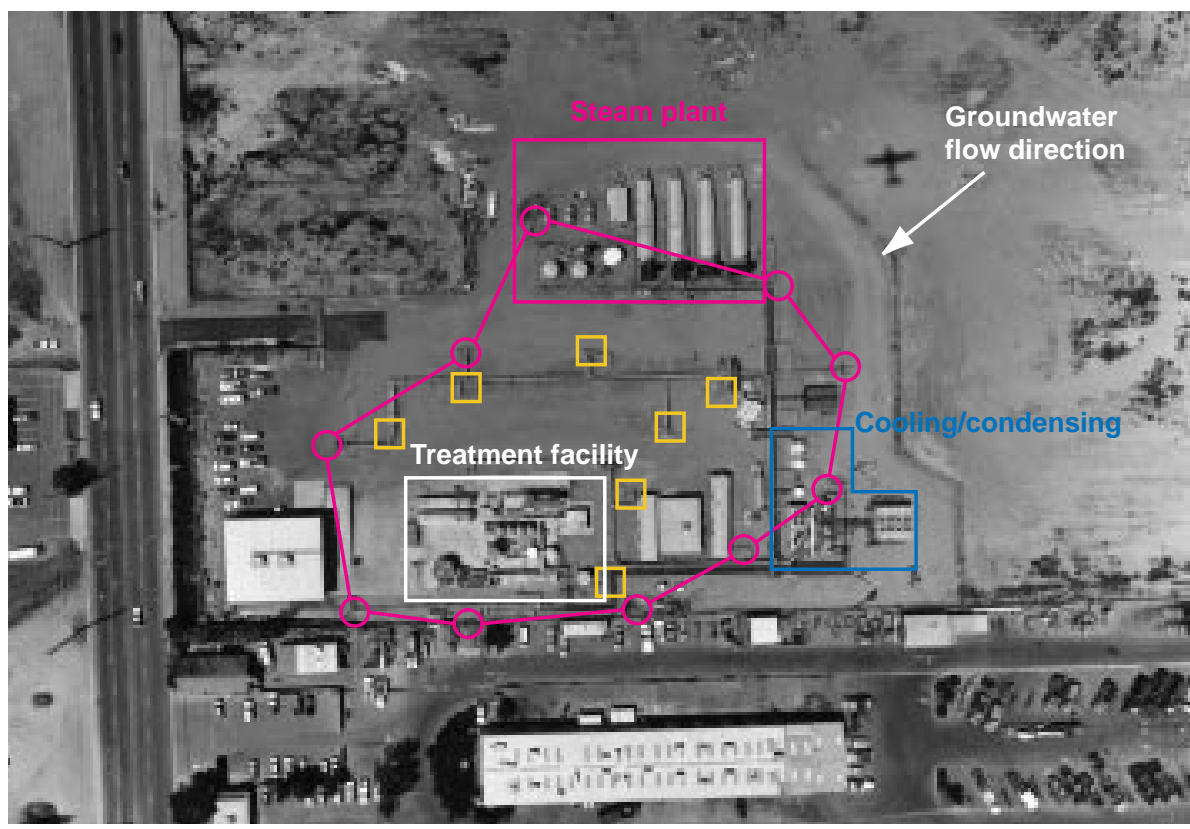

Figure 1 . An aerial view of the Visalia site. Injection wells are shown in magenta, and extraction wells are shown in yellow.

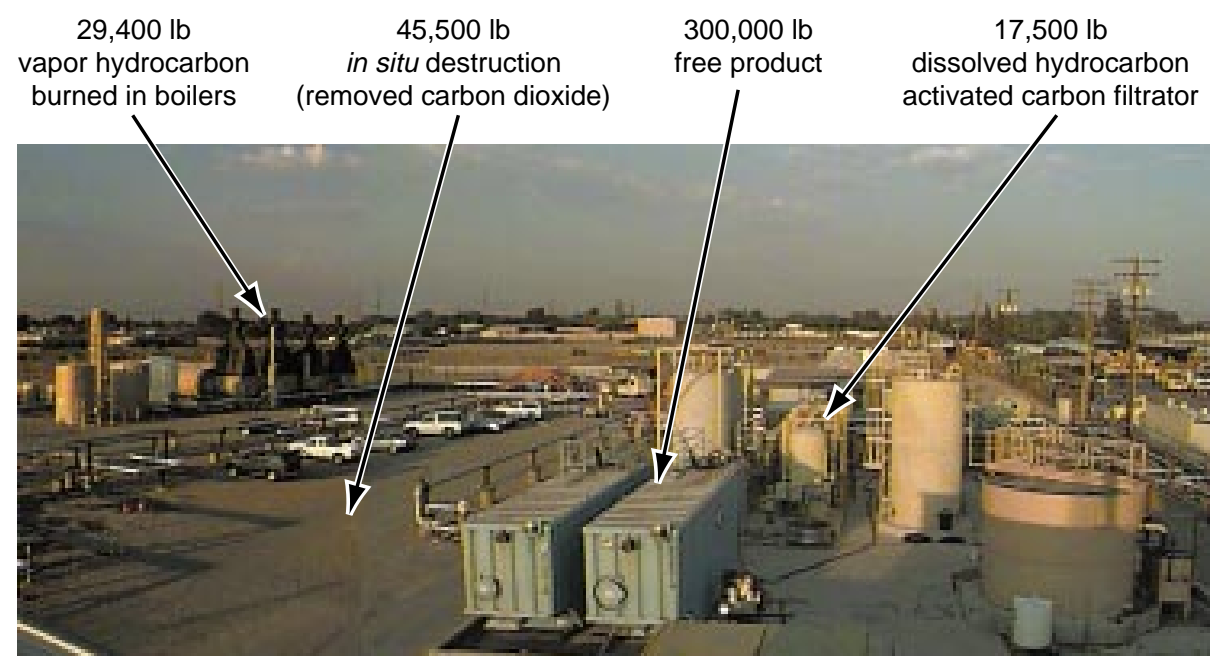

Figure 2. During the first six weeks of operation in 1997, about 300,000 pounds ( 135 metric tons) of contaminated product was either brought to the surface or destroyed in situ at Visalia.

Southern California Edison will treat the liquid "free product" on site and may use it as a lubricant in its operations. of water because contaminants leach out very slowly. When you try to clean them to rinse a soapy sponge. You have to run up with pump-and-treat, it's like trying vast amounts of water through the sponge before all the soap is finally out."

Pump-and-treat systems are relatively inexpensive to operate, but they represent a long-term cost. They offer compliance in a regulatory sense, but the results are not very satisfying because the site is unlikely to be completely cleaned up.

\section{Boiling Off Contaminants}

The dynamic underground stripping technology developed by Livermore and the University of California was first demonstrated in the cleanup of an underground gasoline spill at the Livermore site in 1993 (see Energy \& Technology Review, May 1994, pp. 11-21). Dynamic underground stripping was so successful in this cleanup that contaminants were removed 50 times faster than with the pump-andtreat process. The cleanup, estimated to take 30 to 60 years with pump-and-treat, was completed in about one year. In 1996, the Environmental Protection Agency and other regulators declared that no further remedial action was required.

In this method, the area to be cleaned is ringed with wells for injecting steam at temperatures above $100^{\circ} \mathrm{C}$. Extraction wells in the central area are used to vacuum out vaporized contaminants. To ensure that thick layers of less permeable soils are heated sufficiently, electrode assemblies are sunk into the ground and the ground is heated, which forces trapped liquids to vaporize and move to the steam zone for removal by vacuum extraction. These combined processes achieve a hot, dry, contaminant-free zone of earth surrounded by cool, damp, untreated areas. Steam injection and heating cycles are repeated as long as underground imaging shows that cool (and therefore untreated) regions remain.

Although the initial capital outlay for dynamic underground stripping is higher than for pump-and-treat systems, the 
process saves money in the long run because it is completed much more quickly. Most of the equipment, such as boilers for generating steam, can be rented. Up-front costs include installing the heating wells, renting the equipment, and operating the system intensively for a short period of time. There are no long-term operation and maintenance costs.

That 1993 field trial of dynamic underground stripping cost about $\$ 110$ per cubic yard ( $\$ 140$ per cubic meter), although Livermore scientists believe they could repeat the project for about $\$ 65$ per cubic yard (\$85 per cubic meter). Because contamination at the gasoline spill at the Livermore site migrated downward 40 meters, digging up the contaminated soil and disposing of it would have cost almost $\$ 300$ per cubic yard ( $\$ 400$ per cubic meter). Soil removal and disposal costs are more typically in the range of $\$ 100$ to $\$ 200$ per yard ( $\$ 130$ to $\$ 260$ per cubic meter); pump-and-treat method costs are as high as or higher than soil removal costs.

\section{Unexpected Help}

The Livermore team discovered an unexpected benefit of dynamic underground stripping: it encourages bioremediation. Heating the soil at the gasoline spill site to temperatures above $100^{\circ} \mathrm{C}$ was expected to sterilize it, with the microorganisms that use petroleum products as food expected to return slowly as the soil cooled. But soil samples taken soon after completion of the cleanup revealed large numbers of microbes that thrive in high temperatures (known as thermophiles), apparently because predators and competition had been eliminated.

Bioremediation is an important final step in soil and groundwater cleanups because the microorganisms destroy residual contaminants missed during the initial cleanup process.

\section{Oxygen Is Key to Approach}

With dynamic underground stripping, the contaminants are vaporized and vacuumed out of the ground, leaving them still to be destroyed elsewhere. In fact, about half the cost of a typical cleanup is in treating the recovered groundwater and hauling away and disposing of the contaminated material that is brought to the surface.

'Livermore's hydrous pyrolysis/ oxidation technology takes the cleanup process one step further," explains Aines, "by eliminating the treatment, handling, and disposal requirements and destroying the contamination in the ground." The Visalia pole yard cleanup is the only application of this method to date, but indications are that large-scale cleanups with hydrous pyrolysis/ oxidation could cost as little as $\$ 25$ per cubic yard (\$33 per cubic meter), an enormous savings over current methods. Best of all, the end product of a hydrous pyrolysis/oxidation cleanup with bioremediation as a final step is expected to be a truly clean site.
The hydrous pyrolysis/oxidation process builds on the team's experience with heating large amounts of soil that was gained during earlier work with dynamic underground stripping. To provide the oxygen, steam and air are injected in parallel pipes, building a heated, oxygenated zone in the subsurface. When injection is halted, the steam condenses and contaminated groundwater returns to the heated zone. The groundwater then mixes with the condensed steam and oxygen, which destroys dissolved contaminants. This process avoids many of the mixing problems encountered in other in situ oxidation schemes. In such processes, an oxidizing reagent is typically injected into the subsurface, resulting in the displacement of the contaminant. Without a return process such as steam condensation, the contaminant and oxidant never mix or mix poorly at best.

During the heating process in hydrous pyrolysis/oxidation, the dense, nonaqueous-phase liquids and dissolved contaminants are destroyed in place without surface treatment. The technique improves the rate and efficiency of remediation by rendering the hazardous materials benign by a

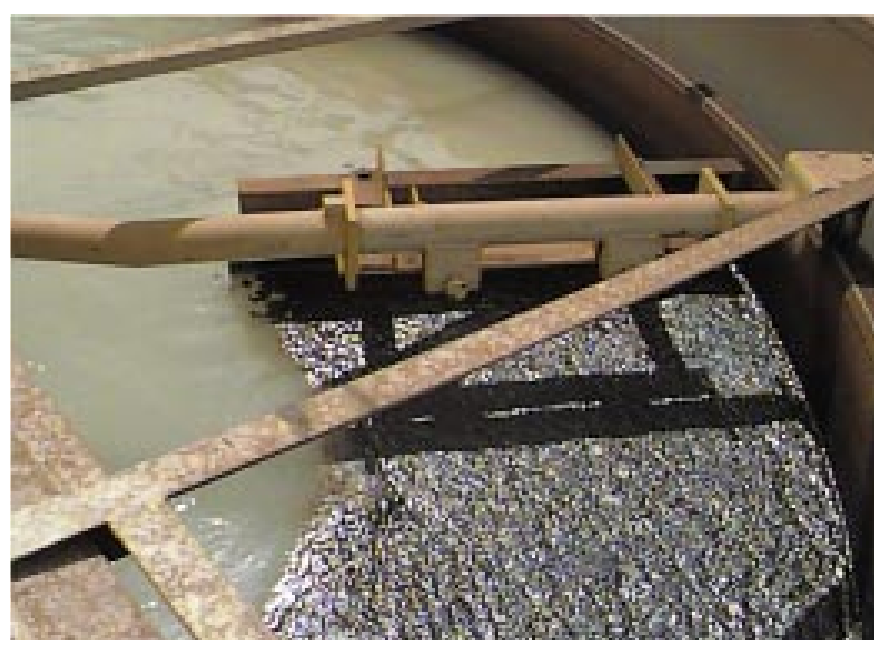

Figure 3. Contaminant floating on water in the dissolved-air-flotation tank (at lower right). Dissolved air forms bubbles that capture and lift free-product contaminant to the surface of the separator. 
completely in situ process. Hydrous pyrolysis/oxidation also takes advantage of the large increase in mobility that occurs when the subsurface is heated and makes contaminants more available for destruction. Many remediation processes are limited by the access of the reactants to the contaminant, making the lack of mobility the bane of remediation efforts in low-permeability materials such as clays.

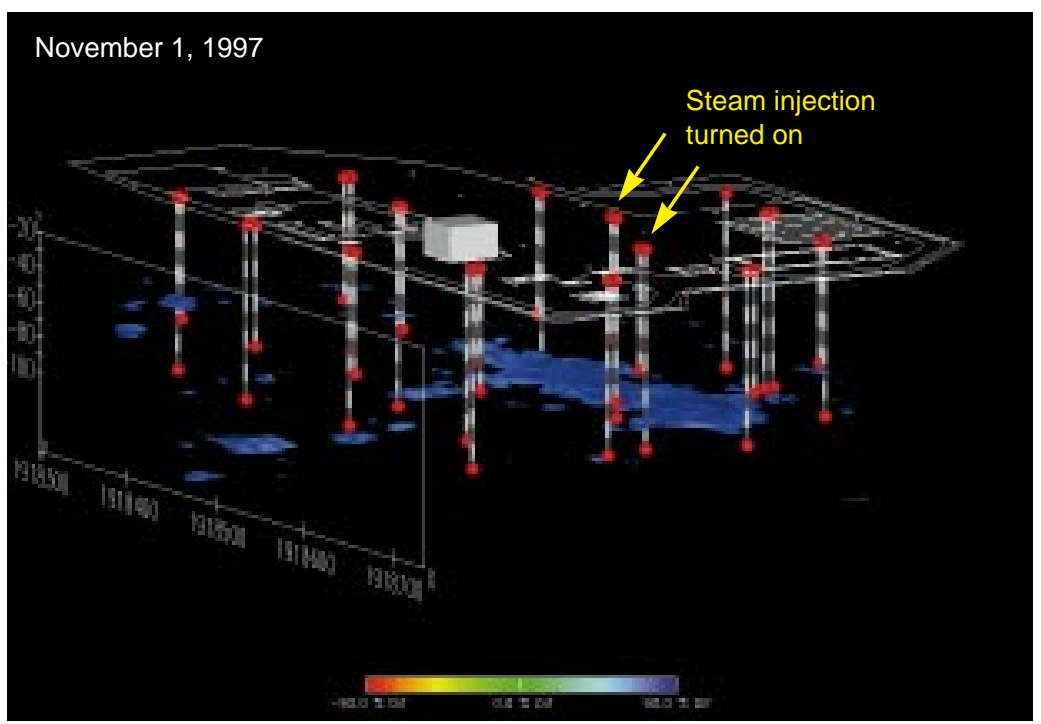

Most early Livermore experiments on the hydrous pyrolysis/oxidation process, funded by DOE, were with trichloroethylene (TCE), a solvent that was widely used in degreasing and other industrial processes. TCE is the most common groundwater contaminant in the DOE complex and in most industrial areas. Unlike gasoline, TCE and similar solvents are heavier than water, which means that they can sink below the water table, making cleanup extremely difficult, if not impossible, with conventional methods.

"The oxidation process occurs naturally, but without heat it is very slow," explains Kevin Knauss, the Livermore geochemist who leads the effort in the laboratory, "so we needed to know how hot the soil had to be." The team learned that with TCE, just a few degrees can make an enormous difference in how quickly the breakdown occurs. At $90^{\circ} \mathrm{C}$, it takes a few weeks; at $100^{\circ} \mathrm{C}$, it takes a few days; and at $120^{\circ} \mathrm{C}$, it occurs in just a few hours. Laboratory results indicated that the contaminants at Visalia would react at similar rates.
Figure 4. Three-dimensional images from electrical resistance tomography data show how resistivity increases when steam injection is under way. After a short shutdown for hardware modifications, steam injection began on October 31, 1997. Steam injected into central wells (arrows) preferentially fills an old alluvial channel (river). Even when a well is not in active use for steam injection, it is kept open with a very small amount of steam; hence, the small "puddles" near inactive injection wells. (Images are courtesy of SteamTech, Bakersfield, California.)

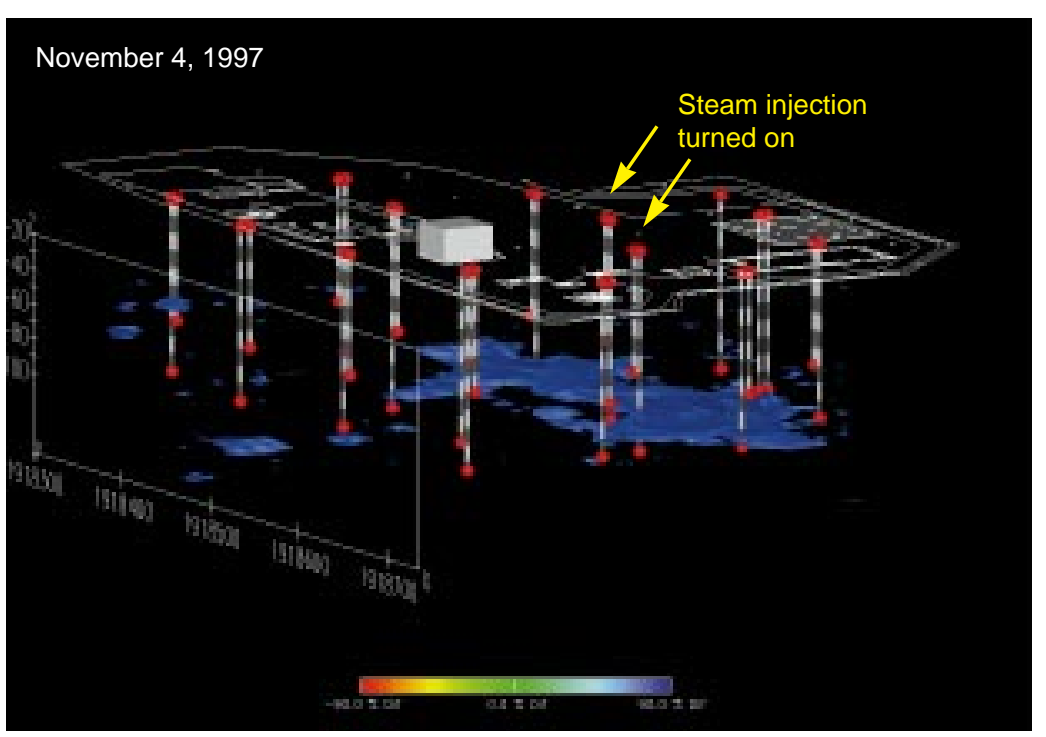


Experiments with dissolved oxygen showed that the oxygen in air is sufficient to degrade the contaminants. Because oxygen is corrosive, pumping pure oxygen into the ground could very quickly damage the piping system, but the less concentrated oxygen from the air is less corrosive and easy to introduce.

The demonstration of hydrous pyrolysis/oxidation at Visalia confirmed the effectiveness of this technology for dense, heavier-than-water groundwater pollutants such as creosote and pentachlorophenol. The method has also been tested successfully in the laboratory on contaminants resistant to cleanup in the past-for example, carbon tetrachloride, a chemical used as a refrigerant and a dry-cleaning solvent, and polychlorinated biphenyls (PCBs), a chemical used in electrical transformers and capacitors.

Project co-leader Aines notes, "This new technology could also be used to mop up methyl tert butyl ether (MTBE), a gasoline additive that has begun showing up in California groundwater."

The method can also be used to clean up groundwater and soils to almost any depth.

\section{Controlling the Process}

Several geophysical techniques were used at Visalia to monitor the underground movement of steam and the progress of heating. One technique was electrical resistance tomography, a technology developed at Livermore, applied during the 1993 gasoline cleanup, and now available commercially. Electrical resistance tomography is an imaging method like a CAT scan that provides near-realtime images of the underground processes between pairs of monitoring wells (Figure 4). Soil electrical properties vary with temperature, soil type, and fluid saturation. For example, higher electrical resistivity is found in more permeable sand and gravel soils. Conversely, less permeable clay soils show lower resistivity (higher conductivity). Baseline measurements with electrical resistance tomography are used to characterize a site and to predict steam pathways.

During treatment at Visalia, daily resistivity measurements supplied a picture of the progress of the steam front and the heated zones. Monitoring the progress of the heating fronts ensured that all soil was treated. Temperature measurements made in monitoring wells revealed details of the complex heating phenomena in the individual soil layers.

To evaluate the progress of the chemical destruction of contaminants in situ, the team also developed field methods for sampling and analyzing hot water for contaminants, oxygen, intermediate products, and products of reaction. Because hydrous pyrolysis/oxidation is an aqueousphase reaction, capturing and evaluating the fluid in that phase is essential. At elevated temperatures, many of the key constituents are sufficiently volatile that traditional sampling techniques are not suitable. The Livermore team developed hightemperature systems that can deliver a pressurized, isolated fluid stream to the surface, where in-line analysis can be performed.

Building on Livermore's experience in using noble-gas tracers to track water movement (see $S \& T R$, November 1997, pp. 12-17), Bryant Hudson designed tracer experiments to help verify hydrous pyrolysis/oxidation in the field. Noble-gas tracers-including helium, neon, krypton, and xenon-were added to injected water and steam to track the movement of the steam (and subsequent condensation to liquid water) and the movement of other gases initially present in the steam (Figure 5). Naturally occurring dissolved gases (nitrogen and argon) provided measurements of atmospheric and native groundwater interaction. Once a "packet" of water had been tagged with gas tracers, it could later be identified

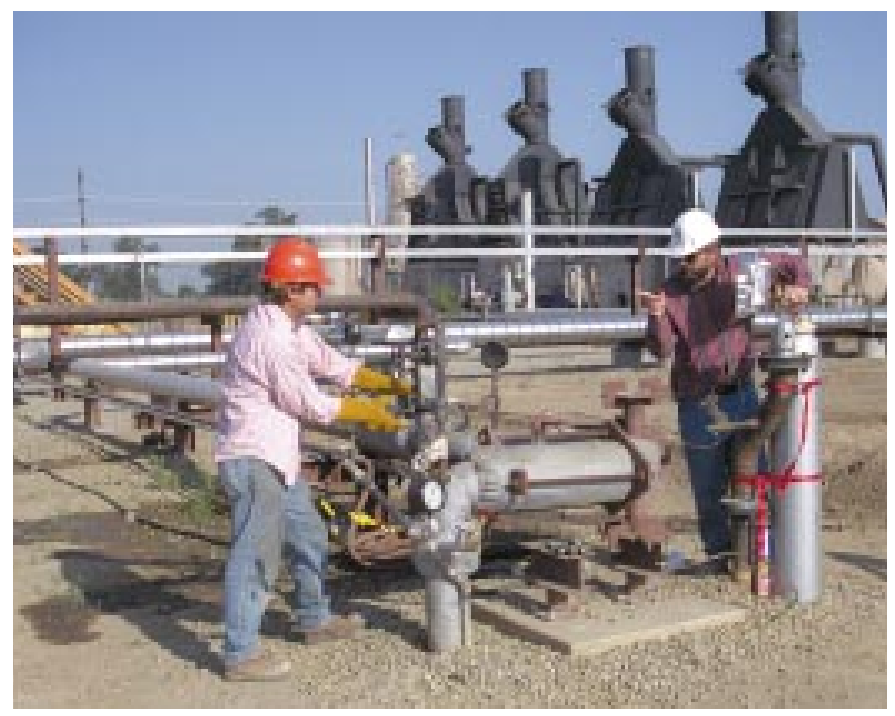

Figure 5. Livermore physicist Bryant Hudson (right), who has developed several methods for monitoring groundwater with noble-gas tracers, adjusts the gas flow with mechanical technician Allen Elsholz. Boilers are in the background. 
by the types and amounts of tracers in it. The tracers thus assisted with many tasks, including:

- Following the injected steam-wateroxygen pattern from each injection well.

- Determining how much mixing occurred.

- Determining oxygen consumption, carbon dioxide production, and transport.
- Correlating the intermediate hydrous pyrolysis/oxidation destruction products with temperature and oxygen. - Identifying the overall isotopic content of the extracted carbon with regard to carbon-14 $\left({ }^{14} \mathrm{C}\right)$ and carbon-13 $\left({ }^{13} \mathrm{C}\right)$.

In soil-gas and water samples, evidence of the progress of hydrous

Figure 6. Gene Kumamoto and Robin Newmark take measurements in Livermore's mini-laboratory, which houses a mass spectrometer, gas chromatograph, and other equipment.
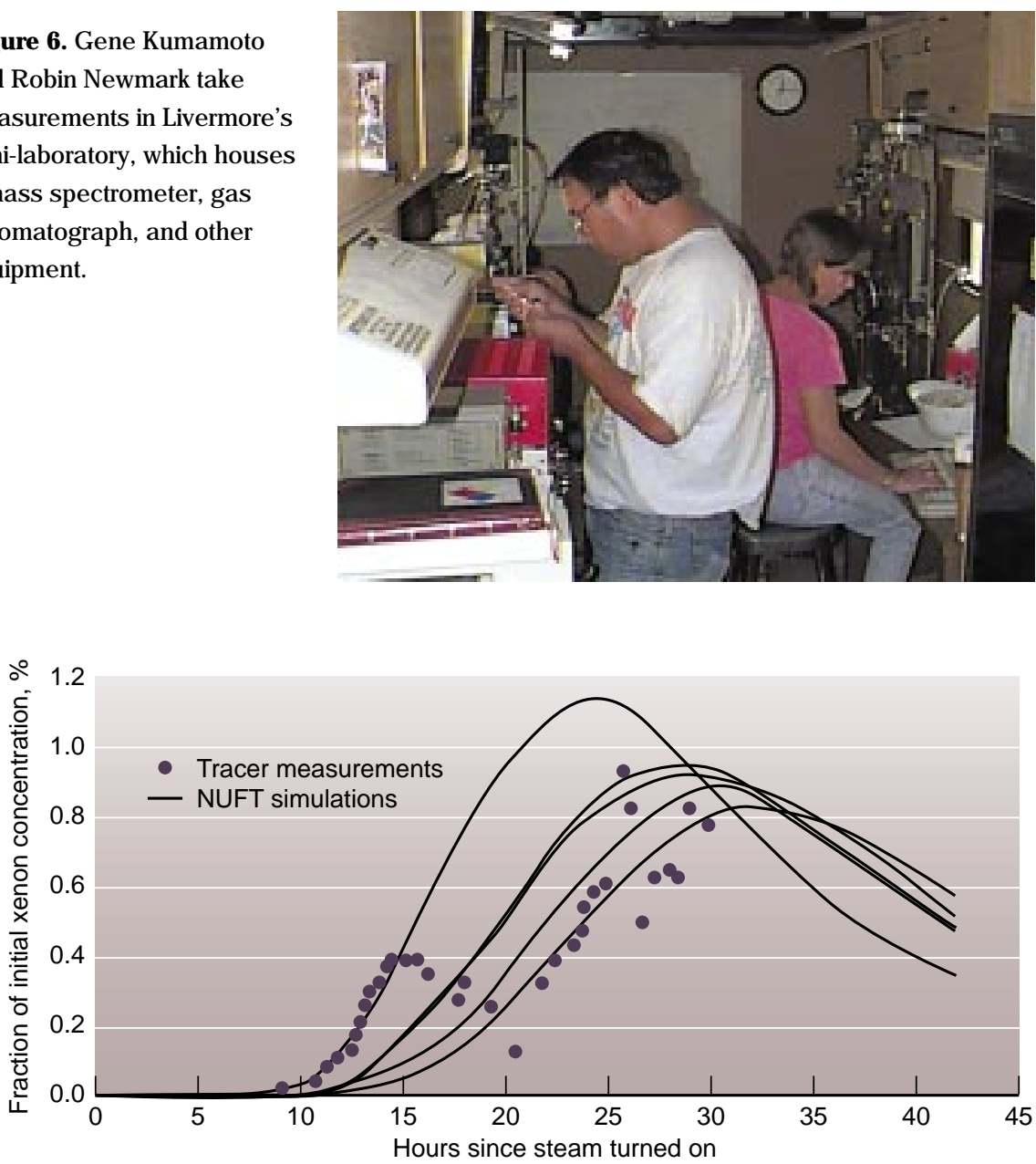

Figure 7. Modeled results using the NUFT code indicate when xenon gas would appear at monitoring wells after having been injected into the subsurface. Curves represent simulated xenon breakthrough concentrations assuming different initial conditions. Observed xenon concentrations (dots) reveal an initial breakthrough, then slight decrease during a drop in injection pressure.

pyrolysis/oxidation (Figure 6) was found in a number of sources, including the disappearance of dissolved oxygen (consumed through the hydrous pyrolysis/oxidation reactions), the appearance of oxidized intermediate products, and the production of carbon dioxide (the final product of this process). Important information on the isotopic content of the carbon in the carbon dioxide was obtained from Livermore's Center for Accelerator Mass Spectrometry. The ratios of ${ }^{14} \mathrm{C} /{ }^{12} \mathrm{C}$ and of ${ }^{13} \mathrm{C} /{ }^{12} \mathrm{C}$ in carbon dioxide from the subsurface were more similar to those of the petroleum-based contaminants than to those of groundwater in the area, indicating that the contamination was being destroyed and converted to carbon dioxide.

\section{Modeling to Predict/Evaluate}

The team used NUFT, a widely used three-dimensional groundwater modeling code developed several years ago at Livermore, to model such important process parameters as mixing of steam, air, and groundwater. In general, simulations with models such as NUFT provide a diagnostic means for anticipating the results of a decontamination scheme in complicated soil environments and, later, for evaluating field results.

In the case of a cleanup such as the one at Visalia, where much of the decontamination occurs in situ and is therefore not directly observable, the noble-gas tracers provide data critical for validating initial modeling results.

"Modeling proved invaluable at Visalia and remarkably accurate as well, compared with results from monitoring wells," explains Newmark. "Livermore models predicted steam and tracer movement to within an hour or two in most instances." (See Figure 7.) 
Modeling also effectively predicted the time of thermal breakthrough, which occurs when sufficient heat has built up in the subsurface for vaporization of contaminants to begin, and steam collapse, which is the opposite phenomenon.

The team found that the ratio of tracer gas to natural air mixed into water was much greater than predicted by the model's initial assumption of no mixing of the atmosphere and steam zone. These data demonstrate that mixing is important and the process is more efficient than envisioned.

\section{From Liability to Asset}

In short order, just months after laboratory experiments were completed, the new hydrous pyrolysis/ oxidation method succeeded at the Visalia site. The project team had brought together Livermore's expertise in underground imaging, noble-gastracer monitoring, supercomputer modeling, and accelerator mass spectrometry to create and verify the field results of a technology to transform the groundwater and soil cleanup process. Far faster than other techniques, the technology provides a relatively inexpensive way to clean up difficult contaminants that plague dozens of sites across the country. For their efforts, the team was recognized with the Laboratory Director's Performance Award in December 1997.

The project team was mindful of the need to make the techniques simple for others to operate and maintain. Integrated Water Technologies of Santa Barbara, California, recently became the first nationwide licensee of Livermore's new cleanup technologies. The company plans to begin using them this year to clean up several Superfund sites.
Work at Visalia is not yet complete. The best estimates today are that cleanup will be completed in a year, with another four years of monitoring the site. Southern California Edison had expected to meet Environmental Protection Agency requirements in about 120 years with traditional pumpand-treat technology combined with enhanced bioremediation. Instead, a piece of real estate that had been a major liability will soon become a valuable asset.

- Katie Walter
Key Words: dynamic underground stripping, electrical resistance tomography, groundwater contamination, hydrous pyrolysis/oxidation, modeling, noble-gas tracers, NUFT code, remediation, soil contamination.

For further information contact Robin Newmark (925) 423-3644 (newmark1@llnl.gov) or Roger Aines (925) 423-7184 (aines1@llnl.gov).

\section{About the Scientists}

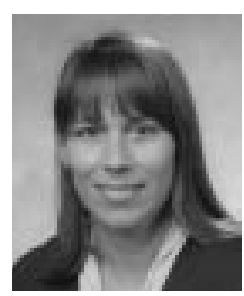

ROBIN L. NEWMARK, leader of the Applied Geology and Geophysics Group in the Earth and Environmental Sciences Directorate, has been at Livermore since 1985 . Her early work focused primarily on borehole geophysics applications. Since 1990, she has been involved in the development of thermal remediation methods and subsurface detection and imaging techniques essential for monitoring and process control of in situ environmental remediation. She earned a B.S. in earth and planetary sciences from Massachusetts Institute of Technology in 1978, an M.S. in marine geophysics from the University of California at Santa Cruz in 1980, and a Ph.D. in marine geophysics from Columbia University in 1985. Author of many papers, reports, and patents, Newmark is associate editor of Geophysics, the journal of the Society of Exploration Geophysicists.

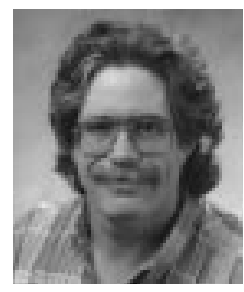

ROGER D. AINES came to the Laboratory in 1984 and is currently leader of the Geochemistry Group in the Earth and Environmental Sciences Directorate. Since 1990, he has been working on the development of thermal remediation methods. Earlier, he gained experience centered on geochemical research and modeling for the Yucca Mountain nuclear waste repository project. Roger received a B.A. in chemistry from Carleton College in 1978 and a Ph.D. in geochemistry in 1984 from California Institute of Technology. He is an author of many papers, patents, and reports related to disposal of nuclear waste and thermal remediation of contaminated groundwater. 


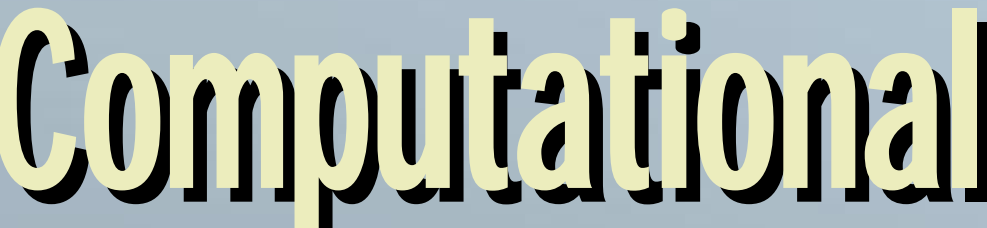 Mecrlanics Moves Anead}

Poiverjul computer cotles, cupuble

of" performing complex structured

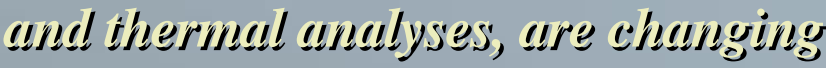

engingering work. IVe: etspubilities

entable problem solving at an!

usprecestented seule.

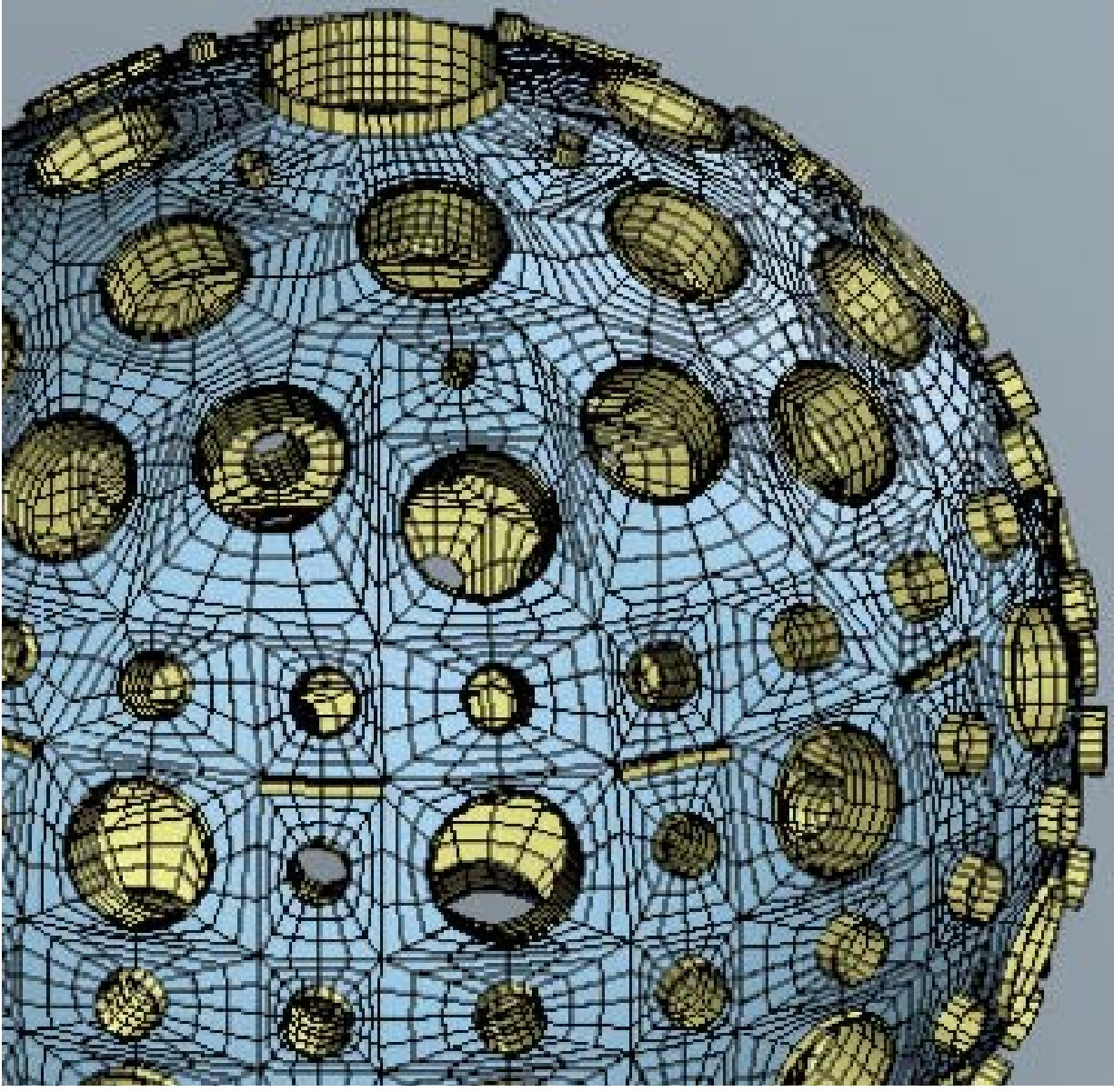

a breakthrough

computer code for parallel machines, was ready for action-the real action that only the most powerful of supercomputers could provide. Action began late last year when the IBM SP2 arrived, the first of a series of massively parallel supercomputers for Lawrence Livermore. Within days, ParaDyn was loaded on the machine and used to simulate, for the first time, a onemillion-element model of a ground shock - a very large problem. The first simulation immediately demonstrated the machine's great power and potential, as well as the efficacy of ParaDyn.

New codes like ParaDyn are an important component of Livermore's effort to ramp up to 100-teraflops (100 trillion floating-point operations per second) power, requisite to solving problems for DOE's Accelerated Strategic Computing Initiative. ParaDyn is the parallel-computing version of DYNA3D, one of Livermore's premiere codes for modeling and predicting thermomechanical behavior.

The development of ParaDyn, ongoing for the past six years, was performed not just in anticipation of parallel computing needs, but because of the forward momentum provided by computational science in the Methods Development Group of Lawrence Livermore's Engineering Directorate. The group was formed in the 1970s to develop modeling tools that were 


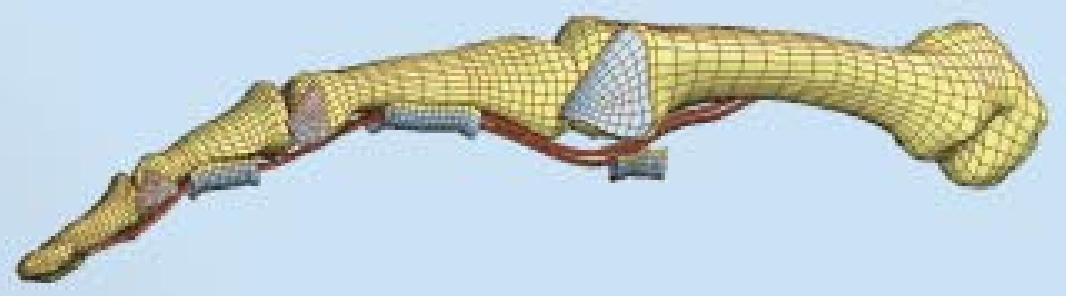

critically needed by Laboratory nuclear weapons projects but were commercially unavailable (see box, p. 17). The broad capabilities of these tools-for analyzing the complex system deformations and nonlinear material interactions-made them valuable commercial products. Over the next 20 years, the group pursued cutting-edge code development and expanded the modeling technology base. They produced an entire family of state-of-the-art software for nonlinear analysis of thermomechanical systems.

And the work continues. As long as the Laboratory's scientific knowledge is needed for weapon systems and other extremely large systems advancements, the group must continue to develop and improve codes. The tools they produce must satisfy the Laboratory's analysis and computational performance requirements. Peter Raboin, leader of the group, puts it this way: "If we end up merely duplicating the work of others and, worse yet, they are solving the same problems faster and better, then we might as well close up the shop." So the group forges ahead, adding to the code family and making existing codes more robust, more accurate, faster, and capable of ever more applications.

\section{Two Classes of Codes}

The Methods Development Group's most prominent mechanical codes are DYNA3D and NIKE3D, which address the behavior of structures as they deform and (possibly) fail, and TOPAZ3D, which addresses the thermal behavior of materials undergoing heating or cooling.

Finite-element codes solve problems by marching them forward step by step. There are two methods for calculating the solution at each new step. One method, called explicit, relies only on data from previous steps. Its equations are not coupled to other variables, thereby keeping to a minimum the amount of computer memory and work required for a solution. DYNA3D, an explicit code, has the ability to handle a large number of mesh elements because of smaller memory requirements than the counterpart implicit method. DYNA3D is suitable for analyzing rapidly changing events - a car collision, for example. However, because explicit methods require very small time steps, DYNA3D is suitable for calculating only brief phenomena (typically less than one second in duration).

NIKE3D and TOPAZ3D are implicit codes. At each step, the unknown future values of all variables must be solved. The equations thus become coupled in a set of simultaneous equations, which are stored in matrix form and must be solved to reach the next step. Solving these sets of equations requires considerable computer memory, thereby limiting the number of elements that can be solved by this method. However, very large steps in time can be taken by the implicit method compared with those taken by the explicit method, allowing events of very long duration to be modeled (typically seconds to years in duration). In addition to dynamic analysis, implicit codes such as NIKE3D and TOPAZ3D can be used to simulate quasistatic events, such as the stresses in a bridge as a car drives across, and static events, such as stress in a bridge under its own weight.

Over time, DYNA3D, NIKE3D, and TOPAZ3D have been improved and applied to an ever-widening range of engineering analyses. DYNA3D is also widely known and used throughout industry, as a result of its dissemination through a collaborator's program (see Energy \& Technology Review, September-October, 1993, pp. 1-5). New applications for all of these codes are developed nearly as fast as the computers available to handle their analyses.

\section{Enhancing DYNA3D}

DYNA3D, suitable for solving problems involving rapid change, has had many applications in safety analysis. Laboratory analysts have used DYNA3D to study crashworthiness in a number of vehicle safety studies, where models of complex vehicles impact roadside safety structures and other vehicles, deforming under the impact. Now, on a project led by physicist Rich Couch, in collaboration with the Federal Aviation Administration and Boeing, AlliedSignal, and Pratt \& 
Whitney, DYNA3D is being applied to a different kind of safety evaluation. Couch and his team are studying the dynamics of fan-blade failure in a jet engine and its effect on the airframe.

When an engine fan blade breaks off, it generates fragments and debris that could further damage the engine or the airframe unless they are confined by the engine's containment system. Although such breakage is rare, the Federal Aviation Administration nevertheless will not certify a new jetengine design unless engine tests, in which a fan blade is intentionally broken during operation, show that the engine casing can contain the fragments. Modeling with DYNA3D reduces the number of expensive tests needed for certifying a new design.
The model required for simulating a fan-blade failure is a complex one. The spinning rotor body inside the jet engine must first be simulated in its steadystate operation. The engine model then undergoes rapid change as a fan blade breaks off, hits other blades, and throws the engine rotor off balance, causing possible critical vibrations in the entire aircraft. The simulation required many improvements in DYNA3D, which were designed and implemented by Edward Zywicz, a computational mechanics specialist in the Engineering Directorate.

To construct the model, computational analyst Greg Kay started with an engine mesh that had been used previously to simulate blade breakoff but had obtained the wrong results. The model's simulation had disagreed with observed test data by

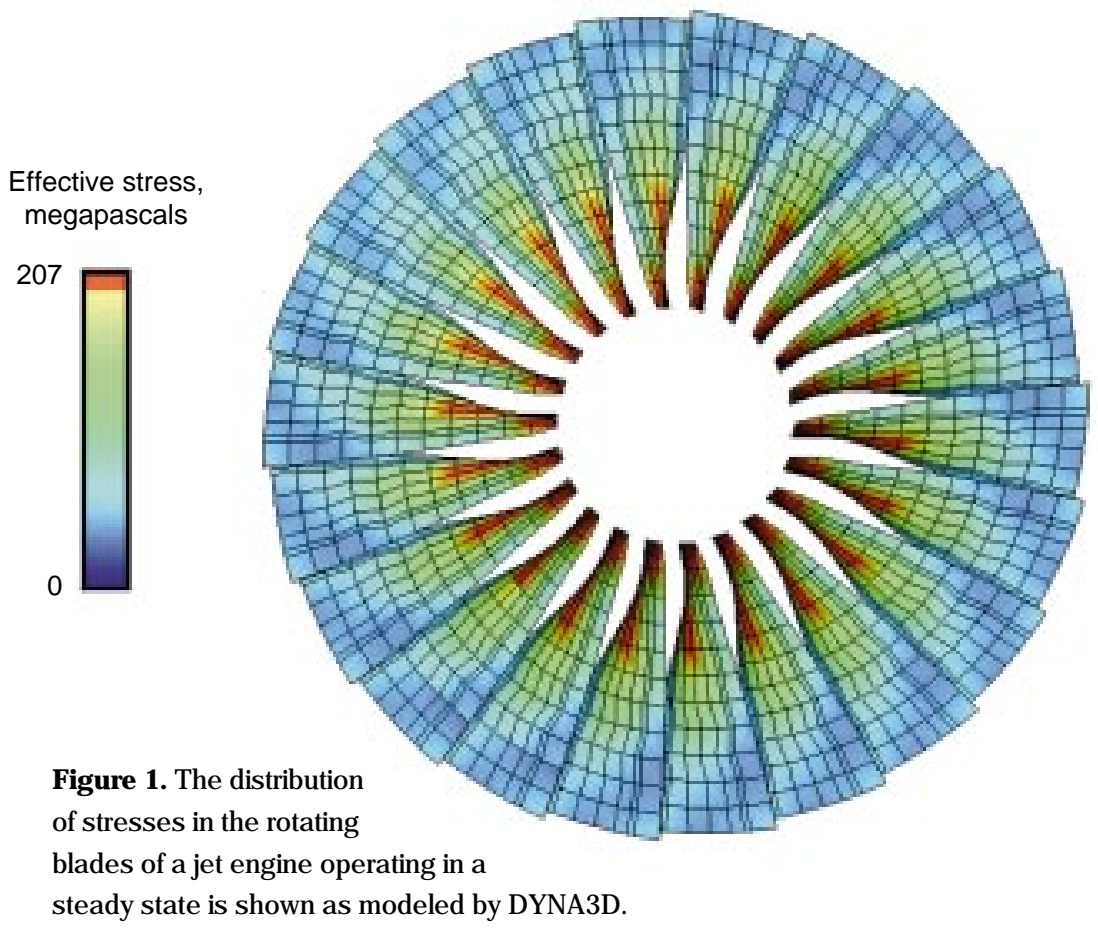

Science \& Technology Review May 1998 
Figure 2 shows the engine approximately one-third of a revolution after the fan blade had broken off.

The simulations made by Kay demonstrate that the DYNA3D code can provide high-confidence simulations of blade failure. Based on those simulations, additional tasks, with the help of partners AlliedSignal and Pratt \& Whitney, were begun in late 1997 to simulate the response of engine containment casings to the blade breakage and subsequent debris collisions.

\section{NIKE3D for Biomechanics}

Joint-replacement surgery, an increasingly common medical procedure, has been hampered by the inadequacies of today's prosthetic joint implants. Replacement prostheses sometimes do not reproduce normal joint movement and, because they have high failure rates, often cause their recipients to undergo additional costly, painful surgery. Attempts to improve the prosthetic designs have been based on limited information garnered from testing and failed implants. To obtain better information, implant designers have needed a way to quantitatively assess the stresses and loads on an implanted prosthesis and the wear and tear on its fabrication materials.

Nonlinear, three-dimensional, finiteelement modeling is a powerful tool for performing such quantitative assessment. NIKE3D, developed for studying dynamic, finite deformations, can model the behavior of joint tissues and bones subjected to different loads and joint movement with and without prosthetic implants. It is being used by Karin Hollerbach, Scott Perfect, and Elaine Ashby, a team of scientists from Livermore's Engineering and Computations directorates, to model both prosthetic implants and human joints. Data from the prosthetic simulations are providing useful information for prosthetic design and, when integrated with data from simulations of human joints, will provide information for evaluating the performance of implanted devices.

Models of implants are based on computer-aided design (CAD) drawings of the prosthesis, from which the finiteelement meshes are made. The models include numerical data that define the properties of the implant materials-

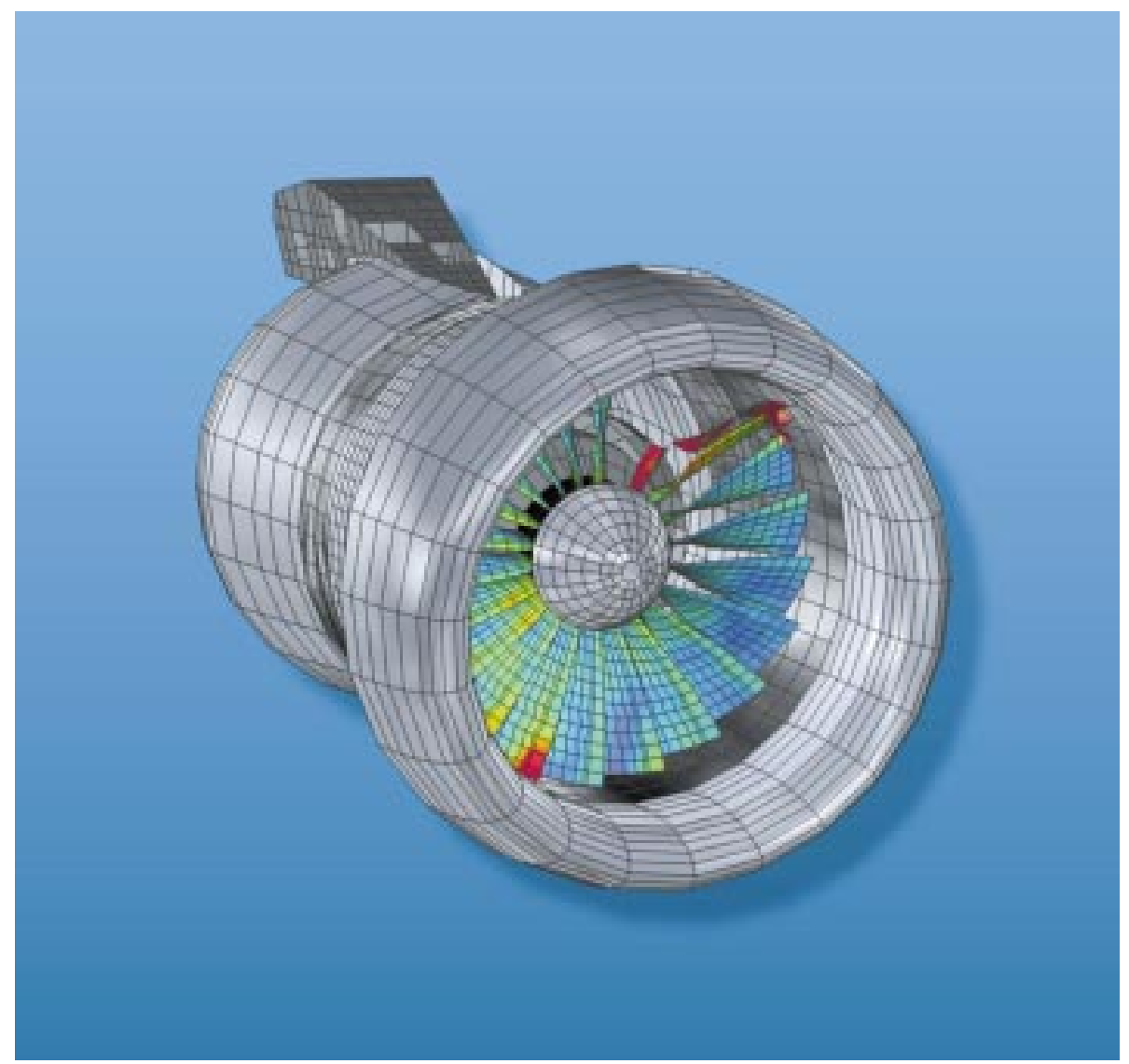

Figure 2. Simulation of a jet-engine blade breaking off. The engine is shown one-third of a revolution after the initial blade release. including polyethylene and several metal alloys in the case of the prosthetic devices being studied-and the forces acting on the joints. For the thumb-joint models that the researchers have constructed (Figure 3), the loads produced during commonly used grasps (the key pinch, screwdriver grasp, and tip pinch) were used as the basis for assessing the performance of three thumb-joint designs. (See $S \& T R$, September 1996, pp. 19-21, for more information on this project.) The stress predictions from the finite-element 
simulations were correlated against clinical findings. The agreement between simulations and clinical findings obtained by the researchers validates the modeling approach and pinpoints the most failure-prone designs. Thus, resulting modeling data can be used for selecting available implants as well as designing new ones.

For the human joint models, the researchers had to develop a process for acquiring human data and converting it into a form suitable for finite-element analysis. They started by scanning a human joint, using computed tomography (CT) to acquire geometric data and bone surface definitions. To these data they added magnetic resonance imaging (MRI) data from collaborators that delineate soft joint tissues. Together, CT and MRI data define how bones and tissues attach to each other. Their resulting images were converted into three-dimensional surfaces using specially developed processing software, and those threedimensional surfaces were then meshed for finite-element analysis (Figure 4).

The researchers are currently working to integrate the data from the

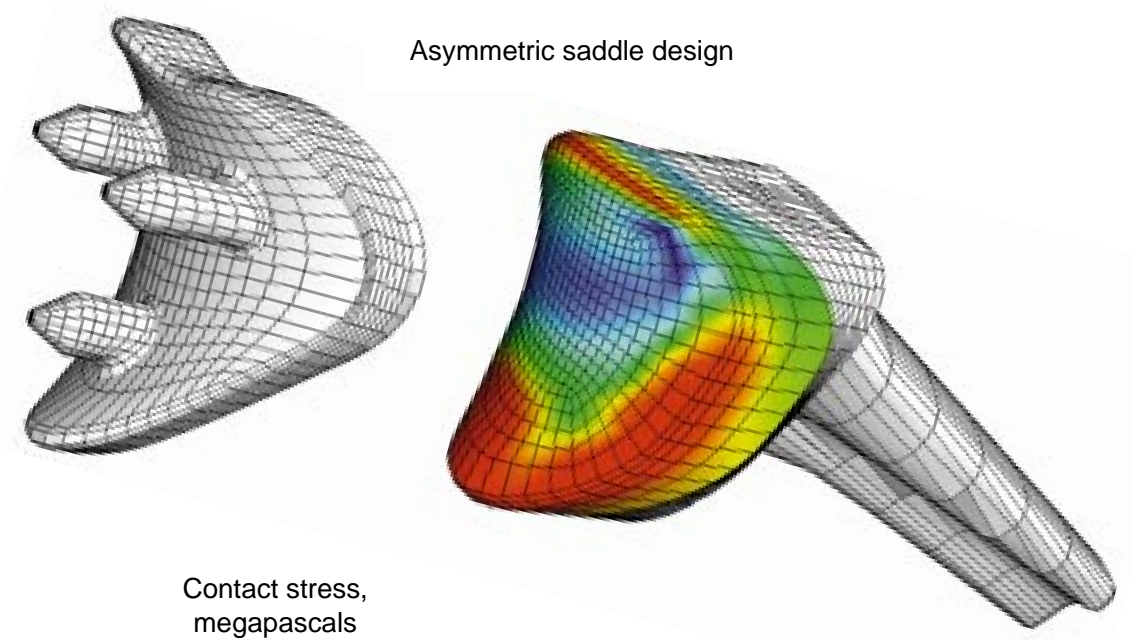

human and prosthetic joint models. These integrated models will be used to calculate the bone stresses resulting from the loads exerted by the implants and make bone-implant interface analyses possible.

\section{TOPAZ3D for Laser Heating}

Before scientists at the National Ignition Facility (NIF) begin performing laser experiments, they must fully understand how the various NIF components will behave in operation so they can design their experiments accordingly. One bit of crucial information they must know is how the NIF target chamber will expand and move as it heats up over the course of repeated laser shots. Attached all around the chamber are series of lenses that focus laser beams onto the target.

Design analyses predicted the steady warming of the chamber and the equilibrium temperatures it would reach during various operating scenarios; the design of the lens assembly around the chamber allowed for these temperature increases. However, other transient temperature effects also must be taken into account, in particular, the periodic

Figure 3. Livermore-developed NIKE 3D is used for finite-element analyses of thumb carpo-metacarpal joint implants. Colored areas show reaction forces experienced by the implants as they would grasp a house key. 
temperature spikes caused by individual laser shots.

These temperature spikes cause a rapid thermal expansion of the target chamber. The chamber then slowly contracts, back to its equilibrium shape in time for the next laser shot. The concern is whether contractions affect the focus of the lenses. Just before a laser shot, these lenses must be in their positions to within tolerances of only a few millionths of a meter.

Wayne Miller, a thermal analyst, was called on to model and simulate the temperature changes of an operating target chamber. He used the heat transfer code TOPAZ3D, developed by Art Shapiro of the Thermo-Fluids Group, in conjunction with NIKE3D to create an analysis model.

The target-chamber model consists of an aluminum inner shell, a concrete outer shell, and aluminum ports through which laser beams are delivered. First, the finite-element geometry was created using TrueGRID, a commercial mesh-generation code. Then TOPAZ3D was used to predict the transient thermal behavior of the model, primarily due to laser energy deposited on the inner wall surfaces, which is then conducted through both shells and convected to the outside air. The thermal results were then given to NIKE3D, which predicted the thermal expansions of the chamber and prescribed the desired motion of the laser lenses for the next shot (Figure 5).

The composite model was used to simulate thermal changes occurring in the chamber when laser shots are fired once every 4 or 8 hours. The 4-hour operating sequence, more challenging to the thermal stability of the chamber, was simulated under various conditions:

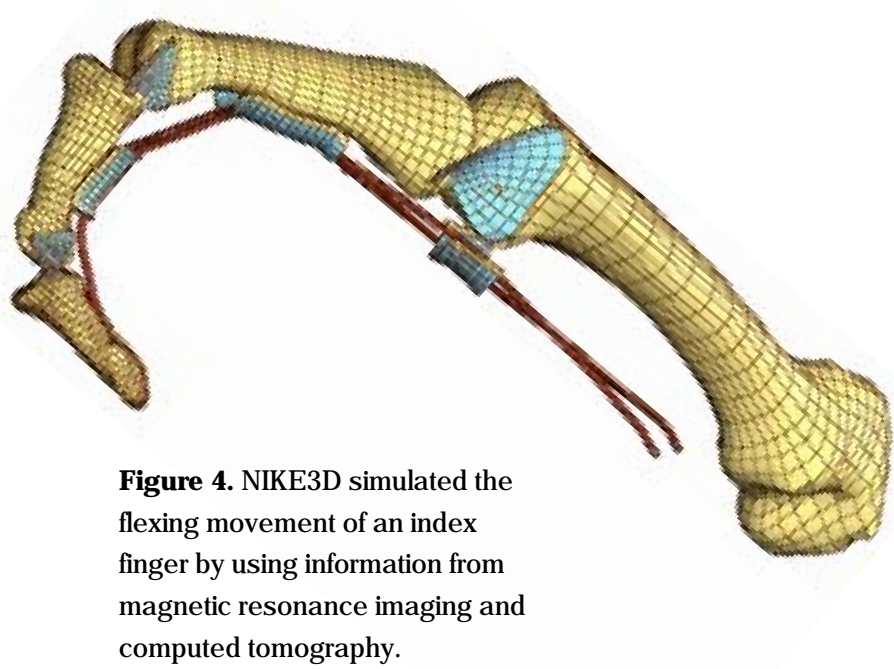

\section{Structural Problems, Computer Solutions}

A Parallel DYNA3D (ParaDyn) simulation of weapons is only one example of finite-element analysis of structural behavior. Other finite-element problems include simulating car crashes and train accidents, falling nuclear waste containers, groundshock propagation, aircraft-engine interaction with foreign debris, metal forming, biomedical interactions, and component designs for cars and aircraft.

The physics of structural behavior can be expressed in mathematical equations that can be translated into problems practicable for solving on the computer. Of the many computational techniques developed and used for solving structural mechanical problems, the one that became the most widely adopted by the 1970 s-and the one that Laboratory computational scientists have advanced-has been the finite-element method.

In the finite-element method, a complex, solid object is divided into an assemblage of simple elements that become the basic units on which the computer calculates the structural behavior. Each element can be made as small and as irregularly shaped as needed to model the object being analyzed. Visually, the collection of elements resembles a wire mesh; the element boundaries are defined by lines that intersect at junctions called nodes. The nodes at each element corner define the movement and deformation of the elements.

The powerful versatility of finite-element codes is best exemplified in the numerous nonlinear material behaviors they can model: elasticity, plasticity, viscoplasticity, viscoelasticity, hyperelasticity, viscous flow, granular flow, thermomechanics, thermodynamic equations of state, composite behaviors, nonlinear foams and solids, void growth, and evolutionary damage accumulation. Simulating all of these behaviors is possible because the finite-element method uses constitutive equations to predict the element stress state based upon changing element deformations. 


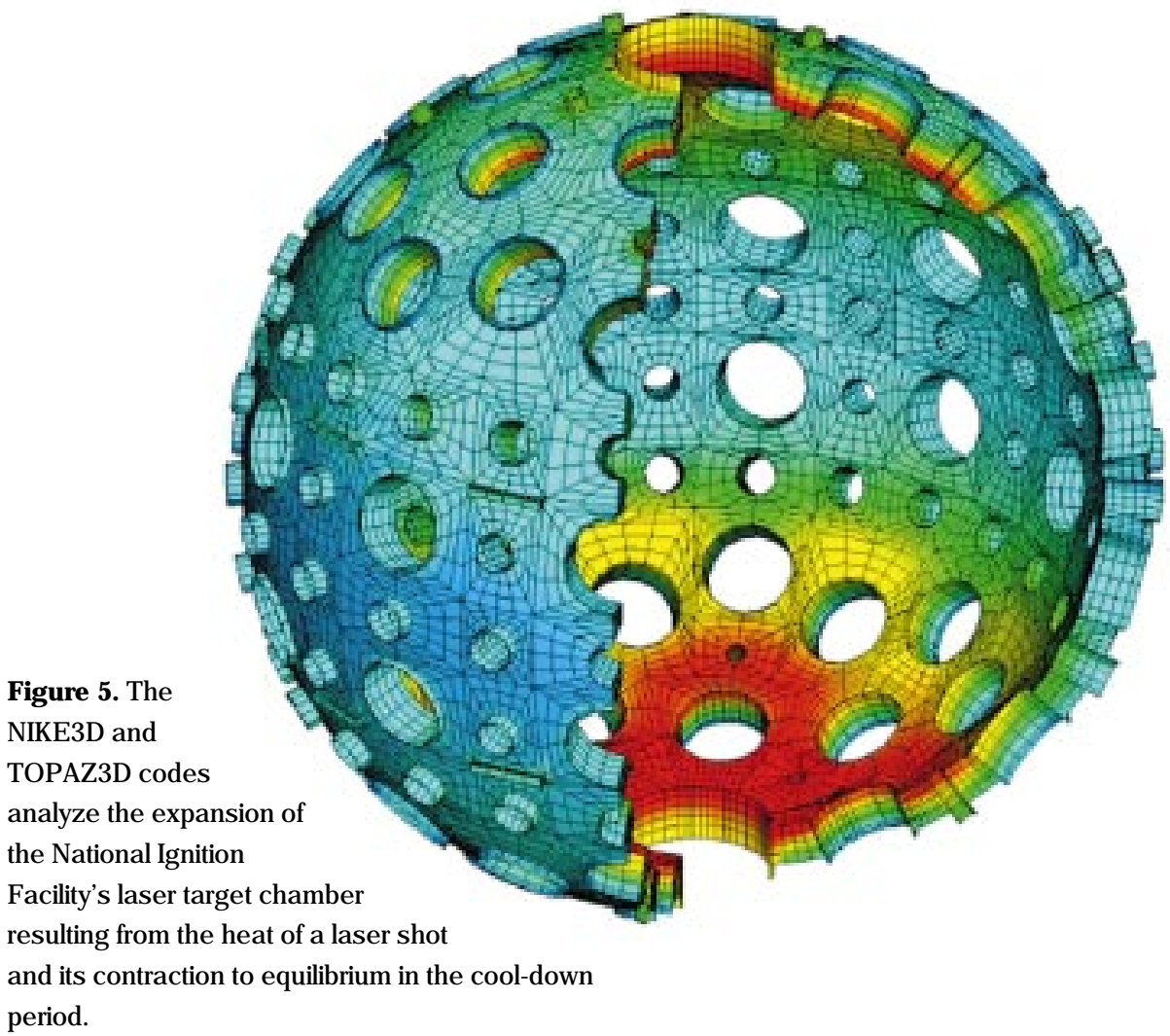

(a)

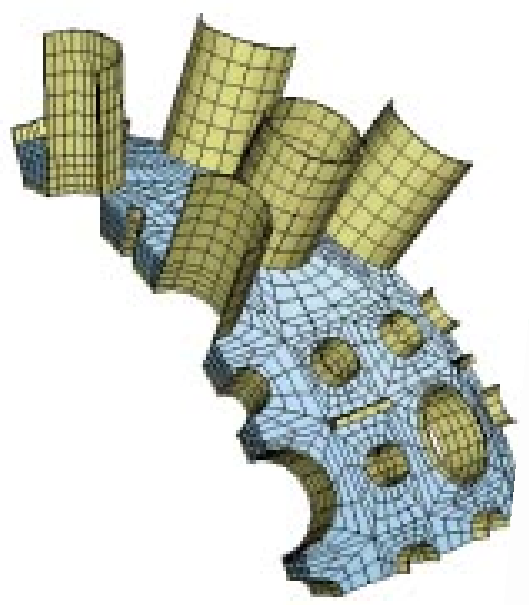

(b)

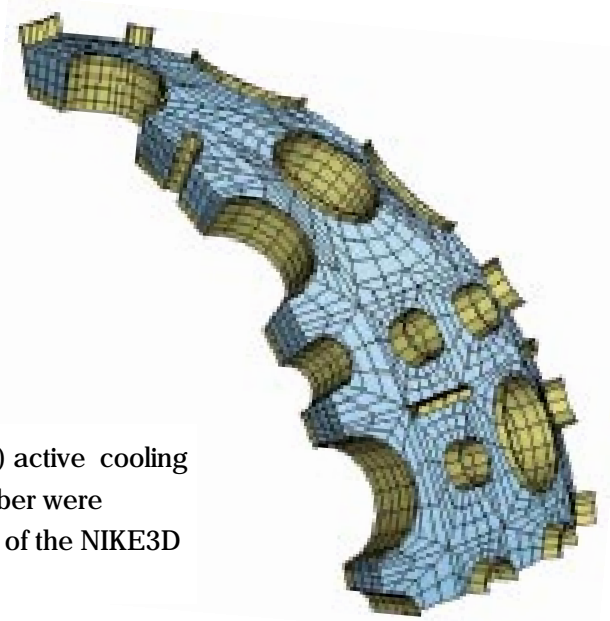
Figure 6. (a) Passive and (b) active cooling methods for the target chamber were analyzed with a combination of the NIKE 3D and TOPAZ3D codes. with laser energies deposited uniformly and nonuniformly, with different outside air temperatures, and with different values for heat transfer from the chamber to the environment.

Because one major goal of the overall analysis was to evaluate two ways of cooling down the chamber, simulations were performed with boundary conditions for passive cooling, in which heat transfers out through radiation and convection, and active cooling, and depends on the installation of a cooling system (Figure 6).

The effects of the target chamber pedestal were also studied. A separate model provided data on how this pedestal grew taller and shrank back down and how this change affected the chamber and ultimately the focusing angle of the lenses.

The results from the simulations for the different operating scenarios, coolingdown options, and pedestal influences were evaluated together to provide details on lens displacements-tangential, radial, or rotational-under different time and temperature conditions.

DYNA3D Becomes ParaDyn

The availability of massively parallel supercomputers, such as the IBM SP2, means that analysts now can solve problems larger by one or two orders of magnitude than was possible with other existing supercomputers. It is now possible and practical for engineering analysis codes to contain meshes with up to ten million elements. Now the limiting factor for problem size and complexity is the amount of time that analysts need to design the mesh rather than the raw speed of the computers.

That boost in computing power depends on capable, efficient parallel codes. Because of the work of a code- 
developer team led by Carol Hoover, such a code, ParaDyn, is now available. As a result, parallel computing in solid and structural mechanics is becoming a powerful tool in computational engineering.

To take advantage of the power of parallel computers, the mesh for a large problem must be partitioned so that the calculations for each part may be performed in parallel by the processors. The more processors working on the problem, the faster the solution is obtained. Multiprocessor calculations depend on the computer program to appropriately divide a problem, to logically sequence its calculations, and to allow communication among the processors so that their solutions can be integrated into a final correct answer.

For computing efficiency, the workload must be evenly distributed among processors so that no processors are waiting on others. Furthermore, calculation time and processor communication time must be balanced; the latter must be limited to a small fraction of the overall computing time. Thus, for optimal efficiency and performance, a problem must be divided using a method that minimizes communication among the processors.

The task of partitioning a problem may be needed more than once at the beginning of a parallel calculation.

Because the problems are dynamic, the mesh may change significantly during the evolution of the deformation, affecting the parallel efficiency. When this happens, repartitioning the mesh and boundary conditions is often necessary. Developing methodologies for these repartitioning tasks is challenging, and research is still in progress in this area.

ParaDyn's success has spun off several benefits to the weapons engineering programs at Livermore. Calculations that previously took several weeks are now performed in a day or less. New models are being generated for mesh sizes between one million and ten million elements-an order of magnitude larger than the largest models possible in the past.

\section{The Next Goals}

With the completion of ParaDyn, the development of parallel algorithms for NIKE3D and TOPAZ3D has begun. "This effort," Raboin explains, "is an even greater challenge.

Developing efficient procedures for solving implicit matrix equations on single-processor computers is already difficult, so imagine the immensity of doing so for parallel processors. That's not to say that projects to couple the DYNA3D, NIKE3D, and TOPAZ3D codes to solve more complex physics problems will be any easier. Those are hard problems, too."

With their experienced research and development, the Methods Development Group is helping to change the nature of engineering work and, in the long term, the very nature of problem solving.

-Gloria Wilt

Key Words: computational mechanics, computer modeling and simulation, DYNA3D, finite-element method, nonlinear behavior, NIKE3D, ParaDyn, parallel computing, solid and structural analysis, TOPAZ3D.

For more information contact Peter Raboin (925) 422-1583 (raboin1@IInl.gov).

\section{About the Scientist}

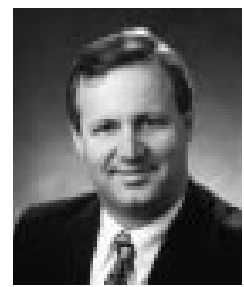

PETER J. RABOIN, joined Lawrence Livermore in 1989, when he became a member of Mechanical Engineering's Applied Mechanics Group. He has been serving as the group leader for Methods Development since 1995. Raboin received degrees in mechanical engineering from Georgia Institute of Technology (B.S., 1982) and Massachusetts Institute of Technology (M.S.M.E., 1985; Sc.D., 1989). He has published papers on thermomechanics and finite-element method. 


\section{Corsica: Integrated Simulations for Magnetic Fusion Energy}

$F_{d}$ OR years, magnetic fusion energy (MFE) scientists have dreamed of an integrated, easy-to-use, and comprehensive family of computer codes that would simultaneously simulate all of the important physics processes that take place in a magnetic fusion reactor. Such a package would be valuable for enhancing the understanding of the extremely complex phenomena observed in experiments. It would also provide a tool to optimally design future MFE experiments.

Although this goal of virtual experiments is still years away, researchers at Lawrence Livermore have made important advances in developing such a comprehensive simulation package. In designing such a code, called Corsica, they have developed techniques to efficiently couple separate physics processes. These techniques plus continuing advances in high-performance computer hardware and software offer the prospect of achieving the goal. Corsica is only one part of a widespread effort, evident throughout Livermore research programs, to simulate to unprecedented levels of accuracy the physical phenomena taking place on scales ranging from atomic particle interaction to global weather patterns.

In fusion, two light nuclei (such as hydrogen) combine into one new nucleus (such as helium) and release enormous energy in the process. One approach to fusion uses a powerful magnetic field to confine a plasma (a gas consisting of charged ions and electrons), generating energy in a controlled manner. To date, the most successful approach for achieving controlled fusion is in a donut-shape configuration called a tokamak.

Future experimental facilities will be much larger than today's research tokamaks and much more expensive, costing as much as several billion dollars each. Although advanced simulations will never replace experimental work, they are needed to optimize the design of future tokamaks and experiments, which will save millions-maybe billions-of dollars. Simulations are also needed to analyze and optimize alternative concepts to the tokamak, such as the small spheromak device that Livermore is now constructing. Scientists consider such simulations essential to resolving several important physics issues, such as how to structure the magnetic fields to produce the maximum pressure and what processes drive electric currents and magnetic fields.
The Need for Integration

"Simulations of individual phenomena-physics 'packages' - now exist as essential tools for analyzing fusion experiments," says Livermore's Keith Thomassen, Deputy Associate Director for MFE. Phenomena such as the equilibrium of the plasma, turbulent transport, stability, and heating, are examples of such processes and are interdependent. Thus, codes that simultaneously describe all these phenomena have these packages "hard wired" together, and the codes are extremely complex. A contributor to this complexity is the disparate time and spatial scales of these phenomena.

MFE processes span a wide range of time scales, from turbulent fluctuations on the microsecond scale to transport processes with scales of seconds to hours. For example, particle velocities parallel to the magnetic field are orders of magnitude greater than those moving perpendicular to the magnetic field. Additionally, MFE models must reflect a range of spatial scales that extend, for example, from the spiral orbit size of an electron to the several-meter-wide tokamak device.

David Baldwin, vice president for fusion research at General Atomics (GA) in San Diego, was Associate Director for Energy Programs at Livermore in the early 1990s when Corsica development began. "The MFE community had done a very good job in developing discreet physics packages but had little experience integrating them. We wanted to provide that capability for the first time but in modular units," he says, "so that, as individual physics packages improved, they could be exchanged. But the entire code would not have to be rewritten."

The inspiration for Corsica, says Baldwin, was Livermore's long-standing LASNEX integrated code for laser fusion that simulates interactions between laser light and its targets. He also notes that Corsica's objective of integrating all the physics phenomena is analogous to that of the Accelerated Strategic Computing Initiative (ASCI), the Department of Energy's effort in the Stockpile Stewardship Program to develop full-system simulations running on new generations of high-performance computers. Indeed, several Livermore Corsica developers are also contributing to ASCI. 
(1) Initial and (2 and 3) converged plasma shapes with self-consistent turbulence.
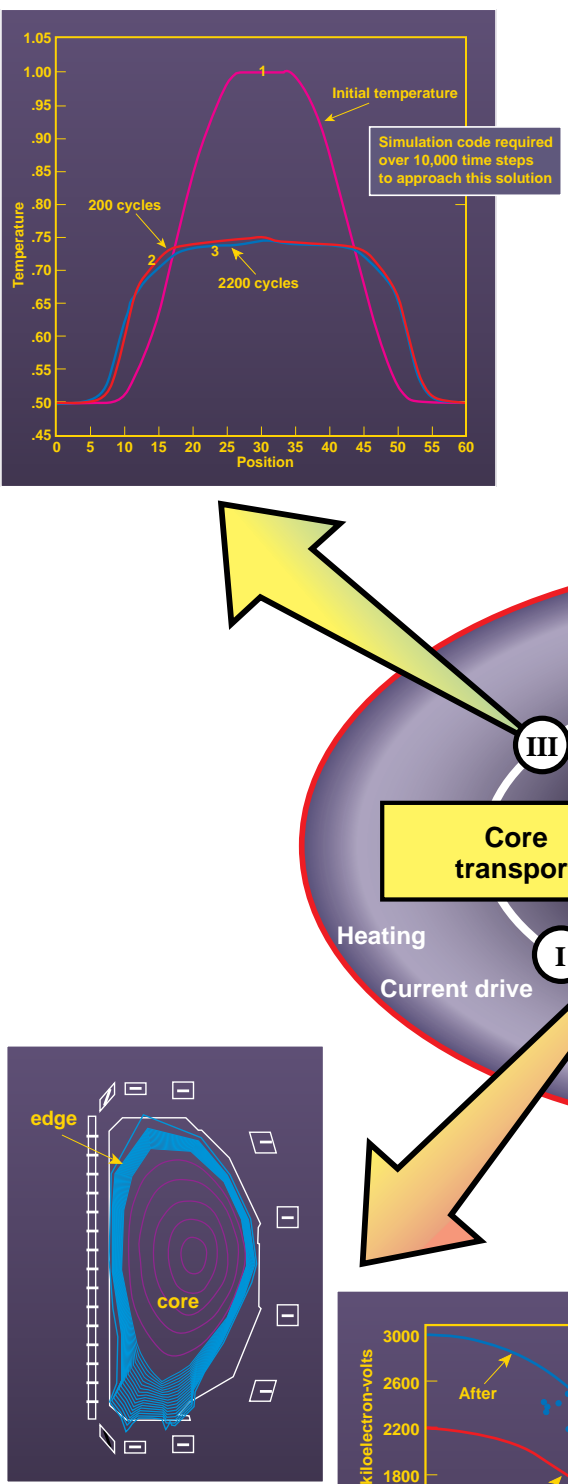

Grid for coupled core-edge transport code.
High-resolution visualization of tokamak turbulence.

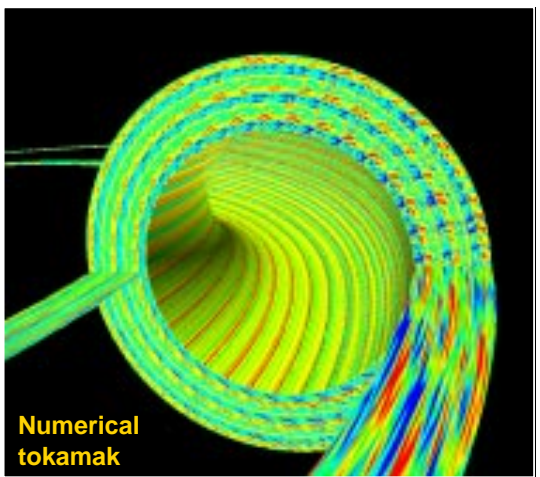

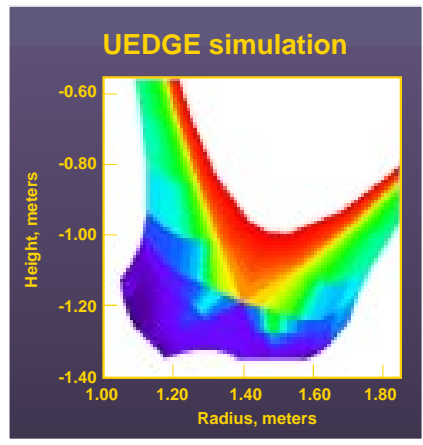
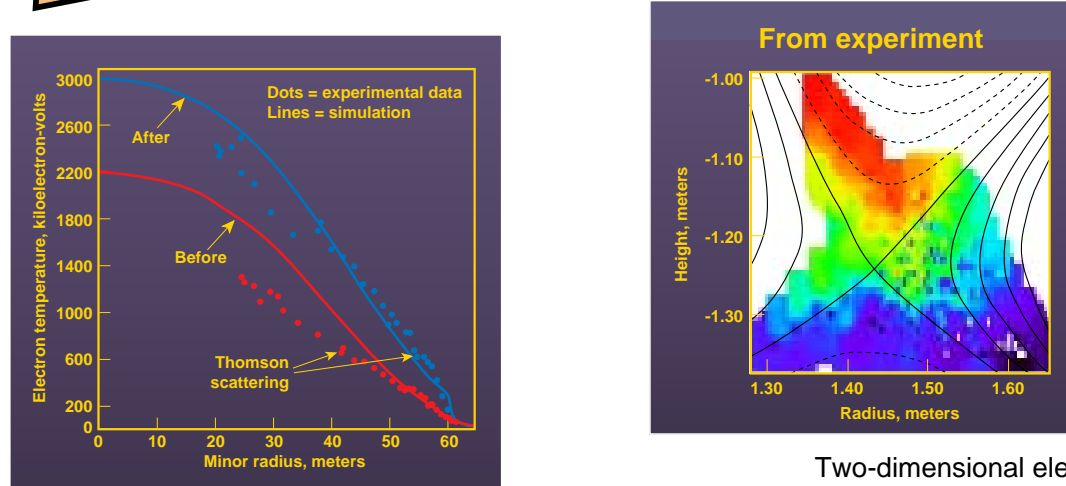

Two-dimensional electron-temperature data.

Temperature before and after transition from low- to high-confinement regime.

The Corsica magnetic fusion simulation code is a prototype for an integrated simulation that would solve models for all aspects of tokamak operations. Roman numerals in the center graphic indicate successive Corsica code releases; images demonstrate their capabilities. 
Corsica I, released in 1994, flexibly coupled onedimensional calculations of particle, energy, and magneticflux transport in the core, or confined region, of the plasma to a calculation of a two-dimensional magnetic configuration. Corsica II, released for testing by sophisticated users in 1995, coupled the one-dimensional core transport calculation to a simulation of the two-dimensional "edge" where magneticfield lines intersect material surfaces.

A still more advanced version, Corsica III, is being developed as funding permits. Its ambitious goal is to couple the evolution of the fusion process to plasma turbulence models for a more comprehensive simulation. The turbulence coupling effort benefits from the sheer computing power of the newest supercomputers as well as from the experience in turbulence of Livermore's MFE theory group. The group participates in the Department of Energy's Numerical Tokamak Turbulence Project, designated a DOE grand challenge.

By handling a wide range of physics with disparate time and spatial scales, Corsica permits more complete modeling of toroidal (donut-shaped) plasmas and other magnetic fusion concepts than previously possible. As a result, the software has been adopted at both national and international research sites. For example, Corsica is used to model plasma confinement in the DIII-D experimental tokamak at GA, where a team of Lawrence Livermore scientists is working. Corsica was used on simulations of the Tokamak Fusion Test Reactor that operated at the Princeton Plasma Physics Laboratory. Corsica has also been used to model the design for the International Thermonuclear Experimental Reactor and Livermore's Sustained Spheromak Physics Experiment.

\section{Corsica Keys on Flexibility}

Livermore physicist Tom Casper uses Corsica to replicate experiments conducted on GA's DIII-D tokamak. He says Corsica helps him obtain a better understanding of past experiments and plan future experiments. He points to the code's flexibility as one of its strong suits. "I can modify the code and manipulate variables, capabilities we don't find in other codes."

In addition, Casper notes that budgets and space constraints limit the number of diagnostic instruments that can be used on the DIII-D tokamak. With Corsica running on a powerful workstation, Casper can add as many so-called synthetic diagnostics as he desires and thereby gain a more complete picture of an experiment.

Corsica's flexibility is provided in part by BASIS, a code steering system developed by Livermore computational scientist Paul Dubois in the 1980s. BASIS also served as the underlying system for LASNEX. Leaders of both the Corsica and ASCI programs have recently chosen Python as the successor to BASIS because of its greater flexibility and its ability to run on many different computers.

Baldwin says Corsica today is "darn good" but still far from the complete simulation code that he and other leaders of the MFE community envision. For that to happen, he says, other major MFE centers need to join forces with Livermore and GA and integrate their own specialized codes, as well as tap the experience of other comprehensive code efforts such as ASCI.

"We want to create a national project that benefits from our experience here," says Ron Cohen, leader of Livermore's MFE theory and computation program. Cohen and others have proposed a "national transport code," a modern code that would draw upon the concepts in Corsica and the vast wealth of physics simulation "building blocks" available nationally. Cohen notes that because the family of MFE simulation codes was created at different research centers in different software languages and on different computers, the effort to modify them and then combine them into a seamless, integrated package will demand strong cooperation among researchers.

In the meantime, Livermore scientists are collaborating with colleagues at GA to combine the best features of GA's transport code with those of Corsica. They hope to carry out their project within the context of the national transport code project.

If the national effort is successful, users will be able to select from many different physics "plug-in" modules to build custom simulations of various-or all-aspects of a magnetic-fusion experiment (tokamak or other configuration). The integrated code would also allow a user to modify experimental conditions and theory parameters or even whole models in real time, without having to use elaborate commands.

"We want to have an integrated, 'living' code that keeps changing and growing as computer capabilities and ideas advance," says Cohen. While it could never serve as a substitute for an actual experiment, such an integrated simulation would undoubtedly save money by enabling betterdesigned and more aggressive experiments. "By combining data from this code with hardware experiments, we' $d$ get the most out of the research dollar," he says.

- Arnie Heller

For further information contact Ronald $\mathrm{H}$. Cohen (925) 422-9831 (cohen2@IInl.gov). 


\section{Device Assembly Facility: New Facilities for Handling Nuclear Explosives}

A S the 18-wheeler slowly eased up to the loading dock under a heavily armed escort, massive steel doors opened from the inside of a partially buried structure. An announcement was broadcast over the public address system alerting specially trained personnel of the arrival of a safe and secure transport vehicle. This special big rig is part of a fleet used by the U.S. government to transport nuclear weapons or weapon components from one secure site to another. Technical specialists stood ready to unload the shipment.

The scene of this activity at the Nevada Test Site is the Department of Energy's newest facility, located 90 miles northwest of the famous Las Vegas strip in a remote part of the Nevada desert. The recently opened Device Assembly Facility, or DAF, offers one of the safest, most secure locations anywhere in the U.S. weapons complex to conduct nuclear explosive operations. Other than the Pantex Plant in Amarillo, Texas, the Nevada Test Site is the only location in the country where special nuclear material such as plutonium can be mated with high explosives.

Under a unique arrangement with the Department of Energy, Lawrence Livermore and Los Alamos national laboratories are designated joint operators and users of the facility. Since the facility's inception, the laboratories have collaborated on every aspect of the facility-including its design, construction, certification, management, and use. Management responsibility is rotated between the laboratories, nominally every two years. "This is truly a joint-lab facility," explains James Page, DAF startup team leader for Livermore. "We share common procedures and integrated hazards analyses and operate with a management team composed of personnel from both laboratories." In contrast, nuclear explosive operations at the Nevada Test
Site in the past were conducted in two separate facilities according to Laboratory affiliation.

\section{Adapting to Challenges}

DAF dates from the mid-1980s, when the weapons laboratories were engaged in active nuclear testing. As with many aspects of the Department of Energy's weapons program, DAF has been adapted to a changing environment brought about by changes in national nuclear testing policy. Designed and built for the purpose of assembling the two laboratories' nuclear test devices prior to placing them underground for testing, the new facility retains its original name. Its mission, however, has evolved since the nuclear testing moratorium began in October 1992.

Instead of the underground test assembly work for which the facility was originally intended, DAF will accommodate other hands-on activities involving high explosives, special

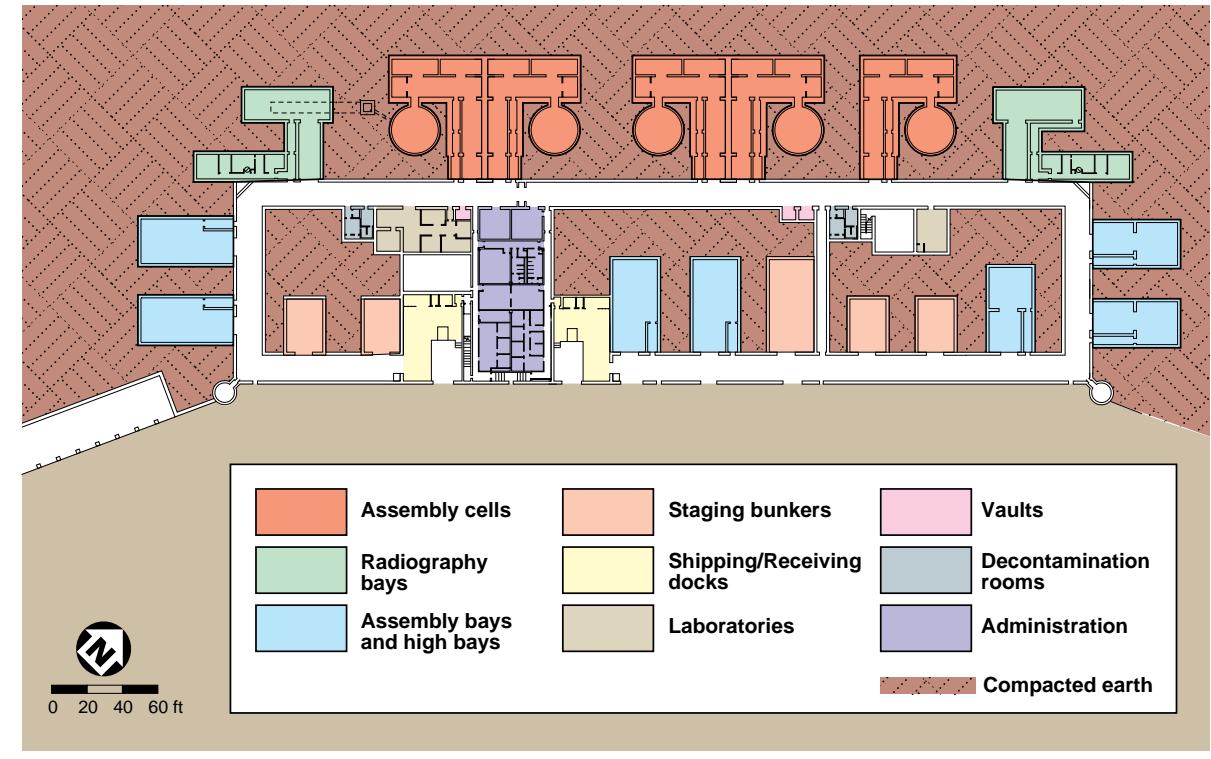

Schematic of the main floor of the Device Assembly Facility at the Nevada Test Site. 
nuclear material, nuclear weapon components, and nuclear devices. These projects, an integral part of DOE's Stockpile Stewardship Program, will include assembly work to support new subcritical (no-nuclear-yield) experiments being conducted nearby as well as stockpile maintenance activities, such as enhanced surveillance technology development and personnel training. These activities will provide necessary data to help maintain the nation's nuclear deterrent. Future use could also include DOE activities to maintain a nuclear emergency response capability.

\section{Anatomy of the Facility}

In a bunker-style arrangement, DAF is a collection of 30 individual steel-reinforced concrete buildings connected by a rectangular racetrack corridor. The entire complex, covered by compacted earth, spans an area the size of eleven football fields (see schematic drawing on p. 23). Because the buildings were designed to accommodate potentially hazardous operations, they meet the most stringent set of safety regulations.

Explains Page, "This facility was intended to provide the safest possible environment for conducting hands-on operations involving special nuclear material and high explosives. The DAF design incorporates the most modern safety and security features in the weapons complex."

The DAF multistructure occupies about 10,000 square meters of usable floor space and consists of operational buildings for

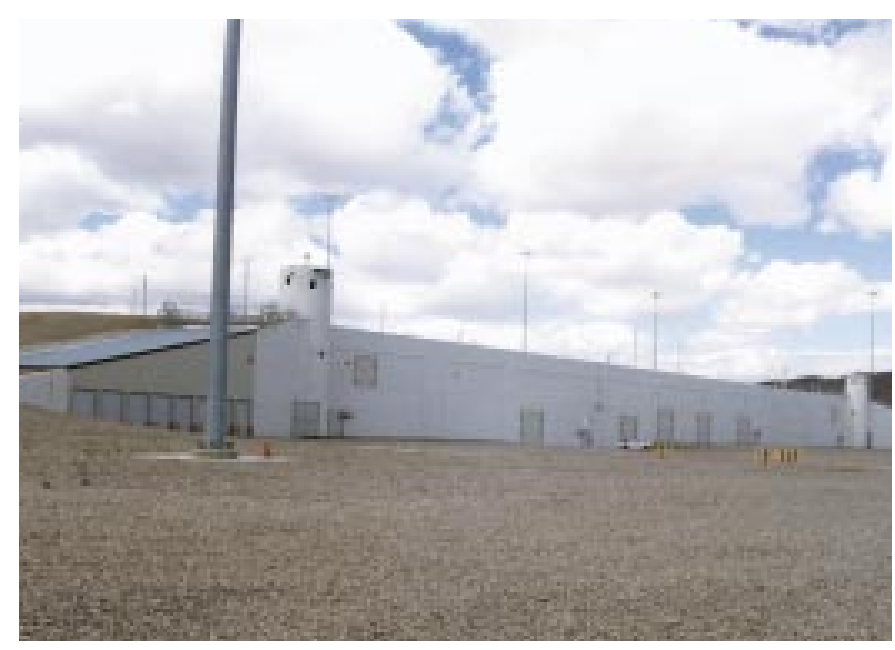

The bunker-style Device Assembly F acility has about 10,000 square meters of floor space in its 30 steel-reinforced concrete buildings. work involving high explosives and special nuclear material and support buildings for laboratories and offices.

Most isolated of the operational buildings are five assembly "cells" for activities involving uncased conventional high explosives and special nuclear material. Four high bays and three assembly bays provide facilities for less hazardous operations, such as those involving uncased insensitive high explosives. When radiography is required to verify the integrity and spatial relationships of objects, a 9-megaelectronvolt, movable-beam, linear accelerator is available in one of two radiography bays. Five staging bunkers provide ample space for interim storage of nuclear components or high explosives. Finally, all materials packages arrive or depart DAF through either of two shipping and receiving bays.

The support buildings include three small vaults for storing small quantities of high explosives or special nuclear material; two decontamination areas; and an administration area containing office space, a conference area, personnel changing and shower rooms, and a machine shop. In addition, two buildings provide laboratory space: one for conducting component, instrumentation, and environmental testing and the other for controlling remote operations of an adjacent assembly cell.

\section{Blast Protection and Containment}

To provide the utmost protection for personnel working within the facility and for the environment, DAF employs several state-of-the-art safety features. Chief among them are blast doors on all operational buildings to mitigate the propagation of an accidental explosion, blast-actuated valves on the ventilation system to prevent the spread of contamination, special ventilation features such as zoned airsupply systems and high-efficiency particulate air filters, and the unique design of the assembly cells.

Indeed, the assembly cells are whimsically called "gravel gerties," after a 1950s Dick Tracy comic-strip character because the roof is overlaid with nearly 7 meters of gravel, said to resemble the original Gravel Gertie's thick curly gray hair. Modeled after the structures at Pantex, where hands-on assembly and disassembly of U.S. nuclear weapons take place, they provide the maximum environmental and personnel protection in the event of an inadvertent highexplosive detonation. The cells are designed to absorb the blast pressure from a detonation of up to 192 kilograms of plastic-based explosives (equivalent to 250 kilograms of TNT, or approximately one-fifth of the explosive energy released in the World Trade Center bombing). Should a detonation occur, 
the gravel gertie would minimize environmental release of nuclear material and propagation of the event to other areas in the facility.

"Although it is extremely unlikely that the cells would ever be required to perform to their full potential," says Page, "their design provides the extra assurance necessary for moderately hazardous activities, such as weapon assembly and dismantlement and some processes for monitoring changes due to aging. In addition, the assembly cells could be used to disable nonstandard explosives, such as a clandestine nuclear device."

\section{A National Resource}

The design of the facility, its remote location, and its safety features make DAF well suited to address new national

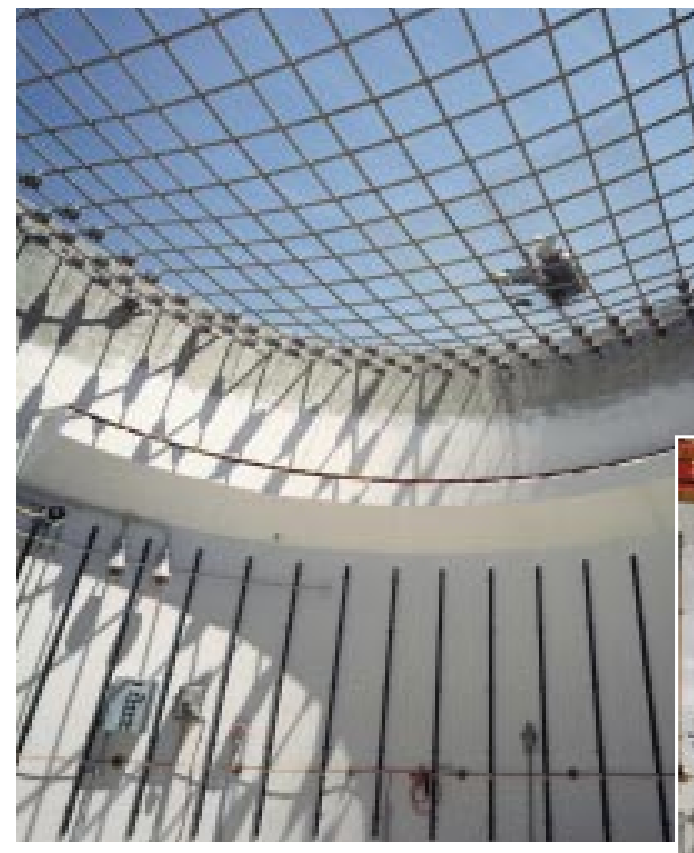

A "gravel gertie" assembly cell during and after construction. The assembly cells were designed to provide the utmost protection to the public, nearby workers, and the environment in the event of an inadvertent explosion. challenges-both predicted and as yet unforeseen-in maintaining the nuclear stockpile. Like Livermore's Laser Programs, started in the 1960s to research electrical power but now studying fundamental physics issues as well, DAF is a valuable national resource whose future applications will likely extend far beyond its original mission.

"DAF is the first facility of this complexity," sums up Livermore physicist Willy Cooper, Nevada Experiments and Operations Program Leader, "for handling unique and potentially hazardous nuclear weapons components and operations that DOE has brought online in several decades. With its 21 st-century focus on environmental, safety, and health considerations, DAF is a functional testimony to the vision of the former generation of weapons scientists, valid today even with a shift in strategic national policy."

- Lori McElroy

Key Words: Device Assembly Facility (DAF), DOE, high explosives, Nevada Test Site, nuclear-explosive operations, nuclear weapon assembly and disassembly, stockpile stewardship, subcritical experiments.
For further information contact J ames Page (925) 423-1195 (jpage@IInl.gov). 


\section{Lunar ice discovery confirmed}

NASA has confirmed the 1994 discovery of lunar ice made during lunar mapping by the Clementine I satellite. Lawrence Livermore physicist Stewart Nozette proposed the novel idea of using Clementine's communications transmitter as a radar to test a theory that ice crystals might be trapped on the moon.

Scientific instruments, including a neutron spectrometer aboard NASA's Lunar Prospector, launched in January 1998 , confirm that at both lunar poles moon dirt is mixed with ice, enough to support 2,000 people for a century. This means the moon could be used as a springboard to space travel.

Contact: Stewart Nozette (925) 424-4964 (nozette1@IInl.gov).

\section{Reno addresses computer security workshop}

"Protecting critical infrastructures and assuring their continued operation" is the central mission of the President's Commission on Critical Infrastructure Protection (PCCIP). Recent workshops put on by Livermore's Center for Global Security Research and Stanford University's Center for International Security and Arms Control (CISAC) developed priorities for the commission's recommendations.

Speaking in Livermore at the last of three workshops, Attorney General Janet Reno gave the keynote address and in it unveiled the National Infrastructure Protection Center, an initiative with a mission to detect, protect, and respond to cyber attacks on the infrastructure. The Center will be an outgrowth of the FBI's Computer Investigations and Infrastructure Threat Assessment Center. The initiative calls for a partnership of federal agencies, private industry, academia, and national laboratories.
Also attending the conference were former Defense Secretary William Perry, General Tom Marsh, chair of the PCCIP, and Michael May, former Lab director and codirector of CISAC.

Contact: Ronald Lehman (925) 423-3711 (lehman3@IInl.gov).

\section{Radio system becomes model}

In acceptance for use of the Lab's Multi-Site Trunked Radio Project, beginning in 1994 and ending in September 1997, DOE recently recognized the project for being the first narrowband digital trunked radio system in the federal government. The network expands radio communications but uses one-half the bandwidth of previous systems and retains encryption. Because the communications are digital, conversations can no longer be monitored by scanners. Maximum spectrum efficiency is achieved by combining reduced bandwidth and wide-area trunking technology. The trunking process manages channel resources by dynamically allocating radio frequencies to users as needed instead of allowing channels to sit idle during periods of low activity. Greater system management and control are also made possible because of the centralized computer network. The new system is now a model for the DOE complex and other federal facilities.

Project manager Clarence "Pete" Davis likens the trunking process to that of waiting in line at a bank for the next available teller-a computer quickly links the radio operator with the first available radio channel. "We've met the new federal regulations for bandwidth reduction, while eliminating channel congestion and increasing privacy and control," says Davis.

Contact: Pete Davis (925) 422-0370 (davis10@IInl.gov). 


\section{Patents}



\begin{tabular}{ll}
\hline P. Henrik Wallman & Diesel $\mathrm{NO}_{X}$ Reduction by Plasma- \\
George E. Vogtlin & Regenerated Absorbent Beds
\end{tabular}

U.S. Patent $5,715,677$

February 10, 1998
A process for reducing $\mathrm{NO}_{x}$ and particulates from diesel engine exhaust by using plasma-regenerated absorbent beds. $\mathrm{NO}_{x}$ is alternately absorbed onto one of two solid-absorbent beds that act as physical traps for particulates. Periodically, a plasma is discharged across the bed for regenerating the absorbing material, followed by air oxidation of the trapped particulate matter. The process can be used for mobile and stationary diesel engines as well as for lean-burn gasoline engines.

A method for compressing data for storage or transmission with few losses and high compression ratios. Given a complex polynomial and a value assigned to each root, a root-generated data file is created one entry at a time. Each entry is mapped to a point in a complex plane. An iterative rootfinding technique is used to map the coordinates of the point to the coordinates of one polynomial root whose value is assigned to the entry. An equational data compression (EDC) method reverses the procedure. The EDC method uses a search algorithm to calculate a set of complex numbers and a value map that will generate the target data file. The error rate between a simple target data file and generated data file is typically less than $10 \%$.

\section{Awards}

Former editor of Science \& Technology Review Ravi Upadhye has been elected a Fellow of the American Institute of Chemical Engineers. Upadhye has been active in the organization, serving as chairman of local chapters and recipient of the society's P rofessional Progress Award for his work in molten salt destruction of high explosives.
For innovative use of the Internet to securely exchange financial information and pay its bills electronically, the Laboratory has won the prestigious 1998 George Mitchell Payment System Excellence Award from the National Automated Clearing House Association. Innovators behind the system are J ohn Rhodes and Chip Hatfield. Last year, the Laboratory also won an award for these efforts from the International Institute of Business Technologies. 


\section{They All Like It Hot: Faster Cleanup of Contaminated Soil and Groundwater}

Two complementary technologies developed by Lawrence Livermore are being used to clean up contaminated groundwater and soil at a utility pole treating facility in Visalia, California, in 5 years instead of a planned 120 years. Southern California Edison, the site's owner, and SteamTech, the first site licensee of Livermore's dynamic underground stripping, began cleanup in June 1997.

Livermore is also field testing hydrous pyrolysis/oxidation, a new technique for destroying contaminants in situ. By injecting steam and oxygen and vacuuming out vaporized contaminants, about 300,000 pounds of contaminants were either brought to the surface or destroyed in situ during the first six weeks of operation. That figure contrasts sharply with the 10 pounds per week that Southern California Edison had been removing with conventional cleanup methods. Electrical resistance tomography (another Livermore development), noble-gas tracers, and analyses of extracted gases are being used to monitor steam injection, underground temperatures, fluid movement, and in situ destruction of contaminants.

Contact: Robin Newmark (925) 423-3644 (newmark1@IInl.gov) or Roger Aines (925) 423-7184 (aines1@IInl.gov).

\section{Computational Mechanics Moves Ahead}

For over 20 years, the Methods Development Group, consisting of computational specialists in the Laboratory's Engineering Directorate, has been expanding the computer modeling technology base to develop tools needed for analyzing complex, nonlinear material phenomena. The advanced computer codes developed by this group support the highly specialized research needs of Lawrence Livermore scientists. As the codes are continually enhanced to keep pace with the Laboratory's scientific advances, their application range has widened. The article describes some current problems that DYNA3D, NIKE3D, and TOPAZ3D-the predominant methods development codes-are being used to solve.

Contact: Peter Raboin, (925) 422-1583 (raboin1@IInl.gov). 
(C) 1997. The Regents of the University of California. All rights reserved. This document has been authored by the The Regents of the University of California under Contract No. W-7405Eng-48 with the U.S. Government. To request permission to use any material contained in this document, please submit your request in writing to the Technical Information Department, Publication Services Group, Lawrence Livermore National Laboratory, P.O. Box 808, Livermore, California 94551, or to our electronic mail addressreport-orders@llnl.gov.

This document was prepared as an account of work sponsored by an agency of the United States Government. Neither the United States Government nor the University of California nor any of their employees makes any warranty, expressed or implied, or assumes any legal liability or responsibility for the accuracy, completeness, or usefulness of any information, apparatus, product, or process disclosed, or represents that its use would not infringe privately owned rights. Reference herein to any specific commercial product, process, or service by trade name, trademark, manufacturer, or otherwise, does not necessarily constitute or imply its endorsement, recommendation, or favoring by the United States Government or the University of California. The views and opinions of authors expressed herein do not necessarily state or reflect those of the United States Government or the University of California and shall not be used for advertising or product endorsement purposes. 

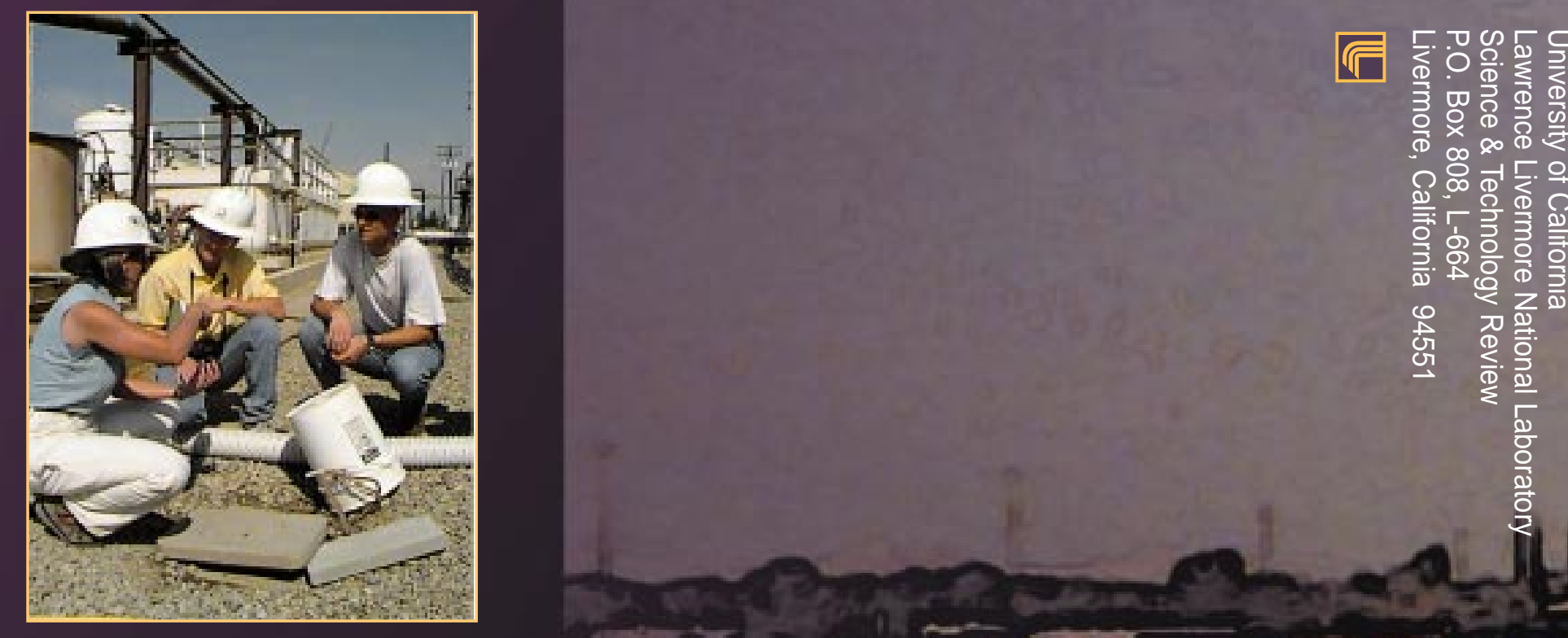

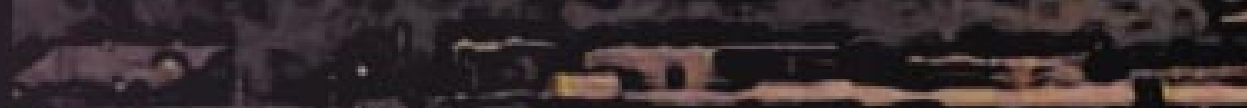

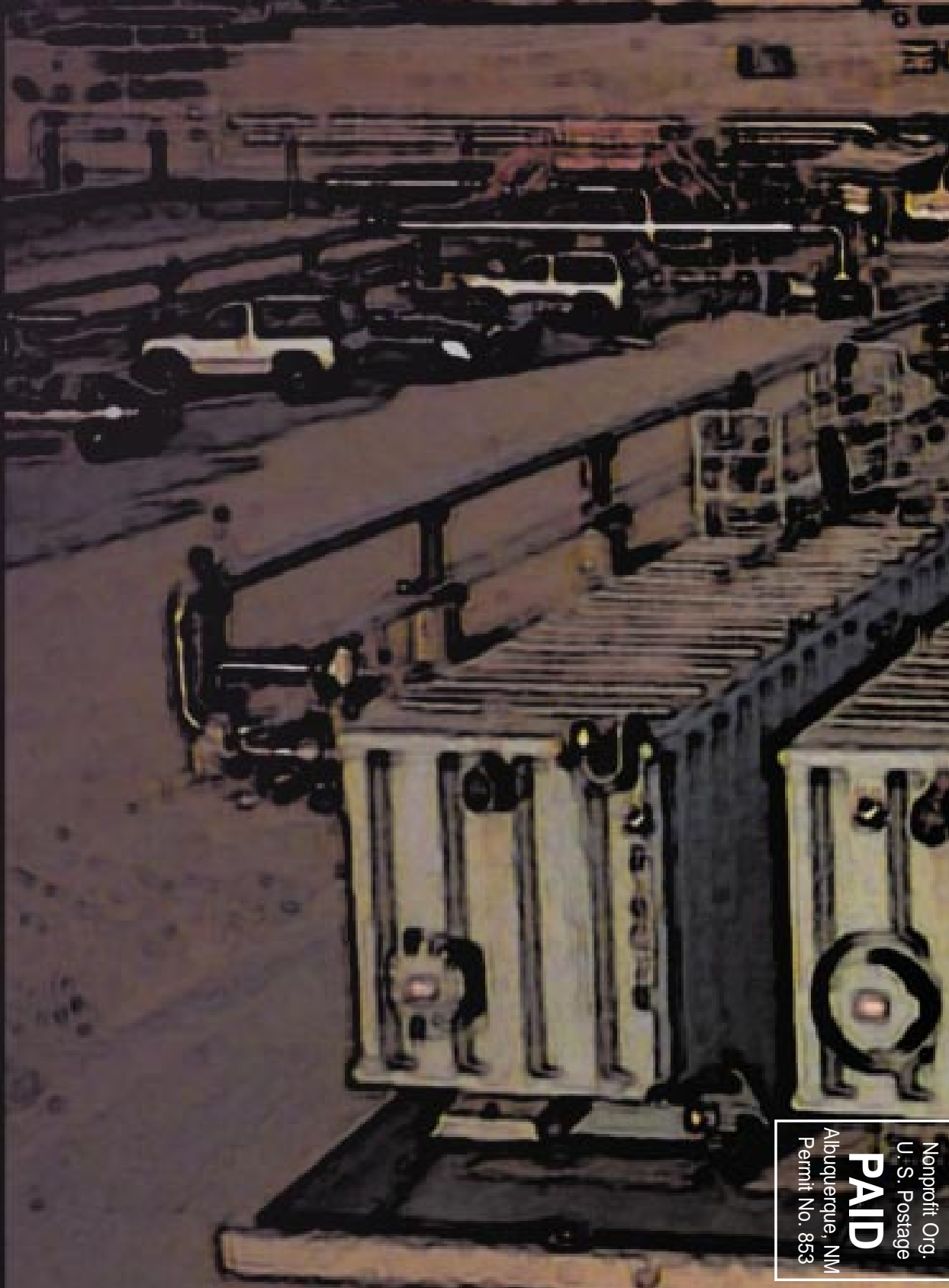

